\title{
Influence of the incorporation of phase change materials on temperature development in mortar at early ages: Experiments and numerical simulation
}

\author{
Mohammad Kheradmand ${ }^{\mathrm{a}, *}$, Romeu Vicente ${ }^{\mathrm{a}}$, Miguel Azenha ${ }^{\mathrm{b}}$, Jose L.B. de Aguiar ${ }^{\mathrm{c}}$ \\ ${ }^{a}$ RISCO - Department of Civil Engineering, University of Aveiro, Portugal Campus Universitário de Santiago, Aveiro, 3810-193 Aveiro, Portugal \\ ${ }^{\mathrm{b}}$ ISISE - Institute for Sustainability and Innovation in Structural Engineering, University of Minho, School of Engineering, Civil Engineering Dept., Azurém Campus, \\ 4800-058 Guimarães, Portugal

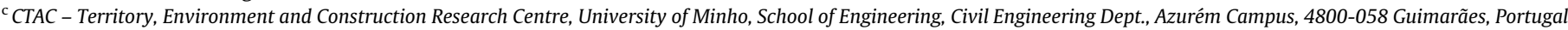

\section{H I G H L I G H T S}

- New strategy for incorporating pristine PCM into the mortar.

- Strength of the PCM mortar is reduced but compatible with structural use.

- Quantitative experimental confirmation of PCM effectiveness in reducing the hydration induced temperature rise.

- Validation of numerical simulation capacity for early temperature development in mortar.

\section{A R T I C L E I N F O}

\section{Article history:}

Received 19 April 2019

Received in revised form 29 July 2019

Accepted 2 August 2019

Available online 7 August 2019

\section{Keywords:}

Phase change materials

Cement hydration

Numerical simulation

Mortar

\begin{abstract}
A B S T R A C T
The present work is focused on a thorough experimental campaign to assess the thermo-physical properties and performance of mortar containing phase change materials (PCMs) with peak melting temperature of $34^{\circ} \mathrm{C}$. This selected melting temperature was targeted to reduce the peak temperature developed in mortar at early ages, induced by heat of hydration of cement. Indeed, $34{ }^{\circ} \mathrm{C}$ is well above normal casting temperatures, yet well below peak temperatures normally attained in massive concrete structures: therefore, this choice would represent a somewhat generalizable choice for attenuating peak temperatures. Due to experimental constraints, the tests conducted herein were performed on mortar (smaller size specimens are possible). However, the methods and findings may easily be extrapolated to concrete.

New preparation and incorporation protocols have been considered for using PCMs into mortar: (i) grated pristine PCM to be dispersed into mixtures; and (ii) macro capsule core of PCM. Three PCM volume fractions of 0,10 and $20 \%$ using the two above mentioned different strategies of incorporation into the mortar were used to prepare a total of five mortar test prototypes. Furthermore, mechanical tests were then carried out on companion specimens to evaluate the effect of incorporating PCM on the compressive and flexural strengths.

The addition of grated PCM (i.e. shredded) in mortar led to enhancement of volumetric heat capacity while maintaining acceptable structural strength. The results revealed that the addition of PCM reduces density, thermal conductivity, and mechanical strength. In respect to the strength reduction, such percentages of incorporation were found to be small enough $(<50 \%)$ as to not compromise the use of such mixtures for structural application.

As expected the tested PCM mortar specimens had a lower peak temperature, as compared to that of the reference specimens (mortar without PCM). Indeed, the 20\% dispersed PCM mixture allowed peak temperature to decrease from $\sim 52{ }^{\circ} \mathrm{C}$ to $\sim 44.8^{\circ} \mathrm{C}$

Complementarily, numerical models were developed and calibrated using the experimental data. The comparison between numerical simulation (using DIANA software) and experimental results revealed a very good agreement of the temperature profiles in the early ages. This allows to validate the capacity of simulating temperature evolution within mortar containing PCM, as well as, to understand the contribution of PCM to reduce the temperature rise coupled with the cement hydration phenomenon. It also represents a baseline methodology for scientists and practitioners to perform parametric analyses for other situations.
\end{abstract}

(c) 2019 Elsevier Ltd. All rights reserved.

\footnotetext{
* Corresponding author.

E-mail addresses: mohammadkheradmand@hotmail.com (M. Kheradmand),romvic@ua.pt (R. Vicente), miguel.azenha@civil.uminho.pt (M. Azenha), aguiar@civil.uminho. pt (J.L.B. de Aguiar).
} 


\section{Introduction}

In concrete, the stress developed at early ages, which can lead to cracking (normally up to 7-14 days after mortar placement), is due to the restrained volume changes, originally associated with different factors [1]: (i) autogenous shrinkage which is induced by water consumption by the hydration process; (ii) drying shrinkage which is induced by evaporation of water during curing period; (iii) thermal expansion/contraction that is due to poor heat dissipation produced by the cement hydration and processes of temperature rise and cooling down of mortar. Early age cracking of mortar [2] may reduce the serviceability and durability [3].

Some strategies such as internal curing, use of specific cements and shrinkage admixtures have been developed to mitigate early age cracking [4]. Most recently, and specifically focusing on thermal cracking, a growing number of research studies have proposed the use of phase change materials (PCMs) as additives [5-9].

The principle of operation of PCMs [10] through heat storage in the scope of mortar applications can be explained with an example: in a concrete mixture containing PCM, when increasing core temperature of concrete (induced by cement hydration heat), temperature reaches the melting point of the PCM, it endures the corresponding phase change and absorbs heat (endothermic process), thus limiting the increase of temperature caused by cement hydration. Therefore, while the heat storage capacity of PCM still exists, concrete temperature tends to remain in the vicinity of the PCM's melting point [5], therefore limiting the temperature rise, and having smaller thermal cracking risk.

Some researchers have investigated methods of incorporation of PCM into cement based materials at laboratory and real scale levels: suspension of phase change material (SPCM) in combination with water [6], self-compacting concrete cubes containing PCMs (dispersed form of incorporation) [11], concrete containing porous aggregates incorporated with PCMs (in the form of vacuum impregnation) [12], mortar and concrete mixes blended with microencapsulated PCM (by direct incorporation) [13], footing member and bridge pier containing PCM (added into the mixture) [14], and cement based materials incorporating microencapsulated PCM [15].

A suitable phase change temperature and a large melting specific enthalpy are two of the main desirable requirements for PCM selection, among other properties. In order to design and optimize the thermal behaviour of a system based on latent heat storage through incorporation of PCM, an adequate knowledge of thermo-physical properties of commercially available or customized PCMs is necessary [16].

Based on the literature review in the scope of the present research, no previous works were found to have focused on the use and comparison of grated PCM and macro capsule core PCM for temperature control in structural concrete. Therefore, in the present research, these two methods of PCM incorporation were compared with a reference case (mortar without PCM) targeting the reduction of hydration-induced temperature swings in concrete at early ages.

For thermal performance testing, five cube prototype mortar specimens were prepared (edge of specimen with $20 \mathrm{~cm}$ length). Two specimens incorporated grated PCM (partial replacement of aggregates by PCM at $10 \%$ and $20 \%$ volumetric percentage), which was directly added into the mixture and casted into a cube prototype. Two other specimens incorporating PCM as an inner macro capsule core (with $10 \%$ and $20 \%$ in volume measured in the same manner as the grated PCM) were studied. A reference mix (without PCM) was also cast into a cube prototype under the same conditions to establish a base for comparison. All specimens were placed under controlled climatic conditions and thermally insulated, as to ensure that the inner temperature development resembled a realistic inner temperature development, similar to the one expected in a real-scale concrete structure.

The development of reliable numerical models and simulations of the transient thermal behaviour of mortar/concrete incorporating PCM is a relevant matter, mostly due to the need to be able to predict performance in scenarios that differ from the limited number of situations analysed through experiments [17].

In the scope of the present study a numerical model was developed using DIANA software [18]. This allows comparison of transient thermal simulation results with the experimental data results of the laboratory specimens for validation purposes. The numerical results of PCM mortar specimens were compared with the reference case (without PCM) to assess their effectiveness over the temperature profiles during the early ages, where generated heat due to the hydration of cement in the mixture occurs at different interfaces and for the whole cross-section of the cubes.

\section{Experimental work}

\subsection{Materials and formulations}

\subsubsection{Choice of phase change material}

The selection of the melting temperature for the PCM for incorporation into the mortar was chosen based on existing knowledge of typical temperature development observed in practice for concrete structures (particularly massive ones). Therefore, the initial selection of PCM material was limited to those exhibiting phase change between $30^{\circ} \mathrm{C}$ and $40^{\circ} \mathrm{C}$, which is a range that is likely to be attained in most concrete massive structures [16], when a casting temperature surrounding $20^{\circ} \mathrm{C}$ is presumed.

Following the five cement classes defined by ASTM C 150 [19], the typical heat of hydration of Portland cement types I, II, III, IV and $\mathrm{V}$ are $350 \mathrm{~kJ} / \mathrm{kg}, 265 \mathrm{~kJ} / \mathrm{kg}, 370 \mathrm{~kJ} / \mathrm{kg}, 235 \mathrm{~kJ} / \mathrm{kg}$ and $310 \mathrm{~kJ} / \mathrm{kg}$, respectively. For discussion purposes, it can be stated that, the average hydration heat of cement is about $300 \mathrm{~kJ} / \mathrm{kg}$. Therefore, the selected PCM needs to have a high latent heat capacity and adequate dosage, when compared to $300 \mathrm{~kJ} / \mathrm{kg}$ brought by cement in the actual mixture, to provide a relevant enough heat absorption effect [3]. Based on the reasoning made so far, pristine PCM named "RT35HC" (from RUBITHERM paraffin RT series) [20] was selected as it is readily available in the market, it does not interact with other concrete/mortar mixture constituents, and also because it can absorb large amount of heat during phase change process [21]. RT35HC has melting temperature ranges between $34^{\circ} \mathrm{C}$ and $36{ }^{\circ} \mathrm{C}$ with heat storage capacity of $240 \mathrm{~kJ} / \mathrm{kg}$, specific heat capacity of $2 \mathrm{~kJ} / \mathrm{kg} \mathrm{K}$, density in solid state of $880 \mathrm{~kg} / \mathrm{m}^{3}$ and density in liquid stage of $770 \mathrm{~kg} / \mathrm{m}^{3}$, according to the information provided by supplier [20].

\subsubsection{Mix design of the mortars}

Portland cement type I class $42.5 \mathrm{R}$ is adopted as the binder from the SECIL company, in Outão, Portugal. River sand was used as inert filler. The grain size distribution of the sand is presented in Fig. 1. The fineness modulus of the sand was $3.2 \mathrm{~mm}$. The preconditioning of all the materials was done according to the recommendations of the RRT ${ }^{+}$program of COST Action TU1404 [22].

The selected PCM (RT35HC) for this research was subjected to DSC experiment in order to provide information on the specific heat capacity of the PCM. A sample with weight of $7.564 \mathrm{mg}$ of PCM (RT35HC) was used. The used DSC equipment (apparatus model Perkin Elmer) has an accuracy of $\pm 0.3^{\circ} \mathrm{C}$. The specific heat capacity was determined following the methodology detailed in Ref. [23]. A heating rate of $2{ }^{\circ} \mathrm{C} \mathrm{min}^{-1}$ was considered. The applied program steps for the test procedure of the sample was the 
following: (i) initial isothermal period at $5{ }^{\circ} \mathrm{C}$ for $5 \mathrm{~min}$; (ii) dynamic heating up to $50^{\circ} \mathrm{C}$ according to the proposed rate $\left(2{ }^{\circ} \mathrm{C} \mathrm{min}^{-1}\right)$. The sample was tested within aluminium crucibles with volume of $40 \mu \mathrm{L}$ under nitrogen $\left(\mathrm{N}_{2}\right)$ atmosphere with a flow of $40 \mathrm{~mL} / \mathrm{min}$. The sample was weighed by an analytical balance with accuracy of $\pm 0.01 \mathrm{mg}$. Sample was sealed in the pan by using an encapsulating press. An empty aluminium crucible was used as a reference.

The specific heat capacity of the PCM was obtained from the DSC. The volumetric heat capacity of the material is calculated by multiplying the real density $\left(880 \mathrm{~kg} / \mathrm{m}^{3}\right)$ and specific heat capacity according to Eq. (1):

$$
C p v=C p \times \rho
$$

Such value ascribes the ability of the material in terms of energy storage in a certain volume while undergoing a gives temperature change. The result of volumetric specific heat capacity on sample taken from pristine PCM (RT35HC) is shown in Fig. 2. The melting peak temperature obtained of $36^{\circ} \mathrm{C}$. It is interesting to note that, the phase change melting temperature is in direct agreement with those specified by the material supplier [20].

Three different mixes have been prepared, without PCM and with different amount of grated PCM and macro capsule core PCM. The formulation of mortars with incorporation of grated pristine PCM allowed volume fraction substitution of 10 and $20 \%$ of the volume percentage of sand using replacement method.

Specific nomenclature has been given to each mortar mixture in order to facilitate identification. In this way, a designation type was created in which "REFM" stands for reference mortar (without PCM), "GPCMM10" stands for mortar incorporated with $10 \%$ Vol. grated PCM and "GPCMM20" stands for mortar incorporated with $20 \%$ Vol. grated PCM. The mix designs of the mortars studied herein, together with their adopted designations (REFM, GPCMM10 and GPCMM20) are presented in Table 1.

The flow table test was used to maintain the mixture workable according to the flow value based on dimeter of standard frustum. The workability tests were conducted through flow table test based on the European standard EN 1015-3 [24]. The mixture is considered workable only when the value of $140 \pm 5 \mathrm{~mm}$ was monitored/recorded for the proposed mixture. The workability tests showed that the incorporation of PCM leads to an increase in water content about $8 \%$ and $16 \%$ for the GPCMM10 and GPCMM 20 , respectively. This can be attributed to the reduced particle size of the used grated PCMs in the mixture compared to the sand

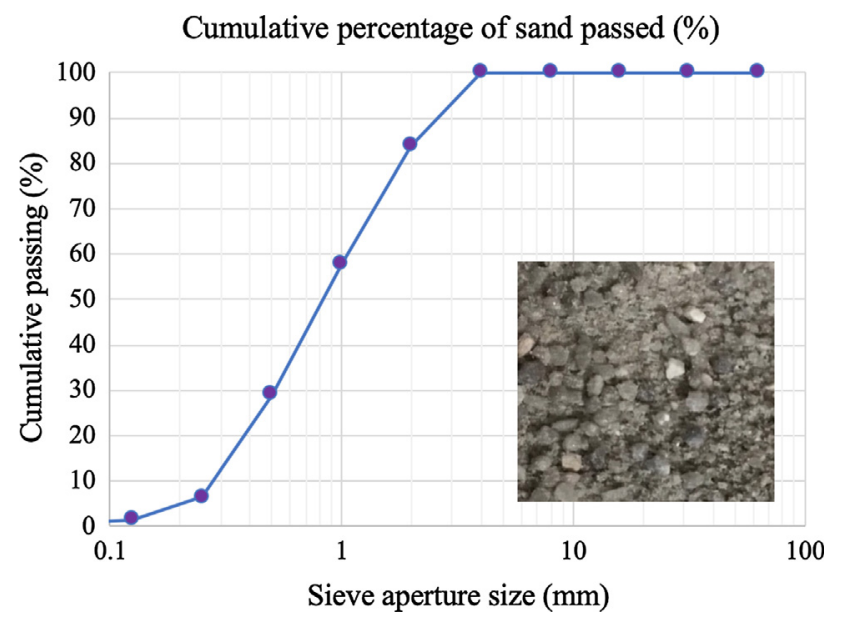

Fig. 1. Particle size characteristics of the sand: the distribution of particle size of the sand with the standard granulometry curve.

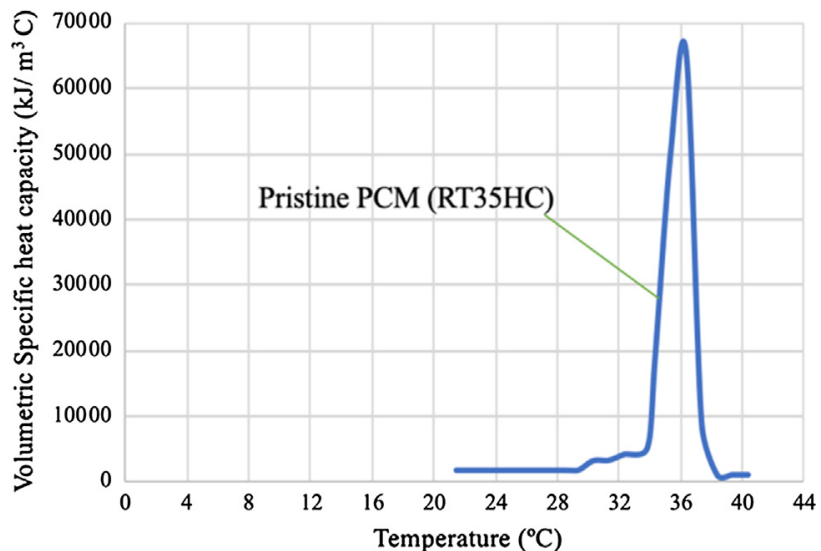

Fig. 2. Volumetric specific heat capacities calculated with the DSC outputs for the pristine PCM (RT35HC)

particles. Therefore, the performance of the mortars wease maintained at satisfactory level in the workability test.

In the scope of this work, a protocol was developed for embedding pristine PCM in the mixture for blends GPCMM10 and GPCMM20, as shown in Fig. 3. The pristine PCM was heated up to $40{ }^{\circ} \mathrm{C}$ to become liquid, see Fig. $3 \mathrm{a}$, then steel containers were filled with liquid pristine PCM. They were then left to naturally cool down at room temperature (around $20^{\circ} \mathrm{C}$ ) for about $30 \mathrm{~min}$ (becoming solid, see Fig. 3b). Then, the PCM was demoulded from steel containers (Fig. 3c). Afterwards, the PCM blocks were grated (powder form, see Fig. 3d) and ready for use in to the mixtures. The granulometry curve for the PCM particles obtained through sieve analysis is shown in Fig. 3e. Fig. 3f, shows the detailed grain size distribution of the PCM. Materials including: Sand, cement, PCM and water were stored at a temperature of $20 \pm 2{ }^{\circ} \mathrm{C}$ prior to mixing. Tap water was used in the production of the mixtures. In order to check the temperature of materials, a laser thermometer (TESTO 875) was used to confirm the desired temperature range $\left(20 \pm 2^{\circ} \mathrm{C}\right)$ for all materials before mixing.

\subsubsection{Preparation procedures}

The mixing procedure was based on the standard EN 480-1 [25]. Twelve prisms were made for each type of mortar (with $10 \% \mathrm{Vol}$. and $20 \%$ Vol. of grated PCM) including the reference mortar for comparison purposes. A total of thirty-six specimens were produced for the density measurement and mechanical tests (compressive and flexural strengths). Additionally, a total of five prototype cubes were produced for thermal tests: Reference mortar, PCM mortars with $10 \%$ Vol. and $20 \%$ Vol. of grated PCM dispersed in the mixture and PCM mortars with $10 \%$ Vol. and $20 \%$ Vol. of PCM in the form of a cubicle macro capsule core. It should be mentioned, that the thermal test for the reference mortar has been repeated in order to verify the repeatability of the result upon similar conditions.

The preparation of all mixtures was carried out according to the step-by-step procedure presented in Fig. 4. Firstly, the

Table 1

Mix design of reference mortar and mortars with grated PCM.

\begin{tabular}{llll}
\hline \multirow{2}{*}{ Components $\left(\mathrm{kg} / \mathrm{m}^{3}\right)$} & Reference mortar & \multicolumn{2}{l}{ Grated PCM mortar } \\
\cline { 2 - 4 } & REFM & GPCMM10 & GPCMM20 \\
\hline Cement Type I -42.5R (SECIL) & 500 & 500 & 500 \\
Water & 245 & 265 & 285 \\
Sand & 1579 & 1435.5 & 1315.8 \\
PCM & 0 & 41.7 & 76.5 \\
\hline
\end{tabular}




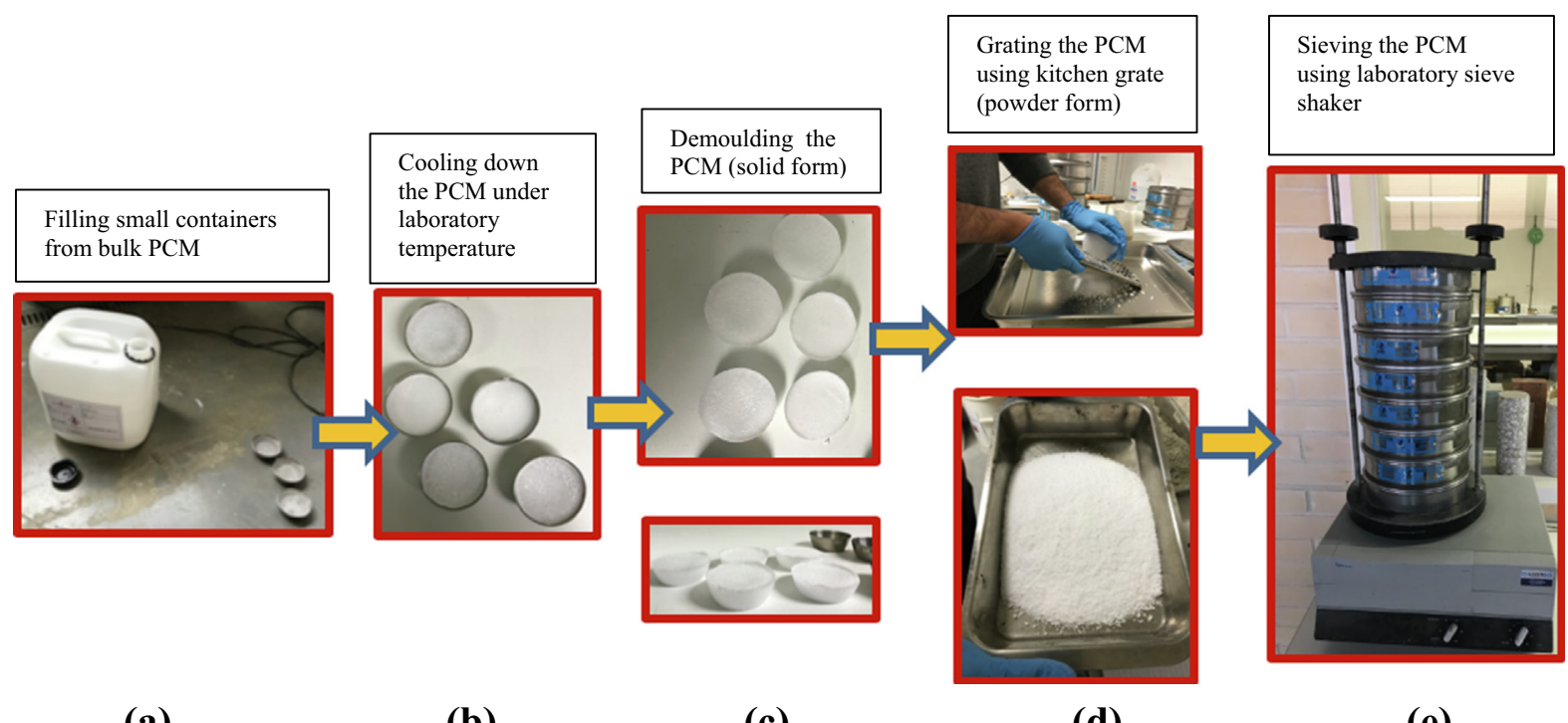

(a)

(b)

(c)

(d)

(e)

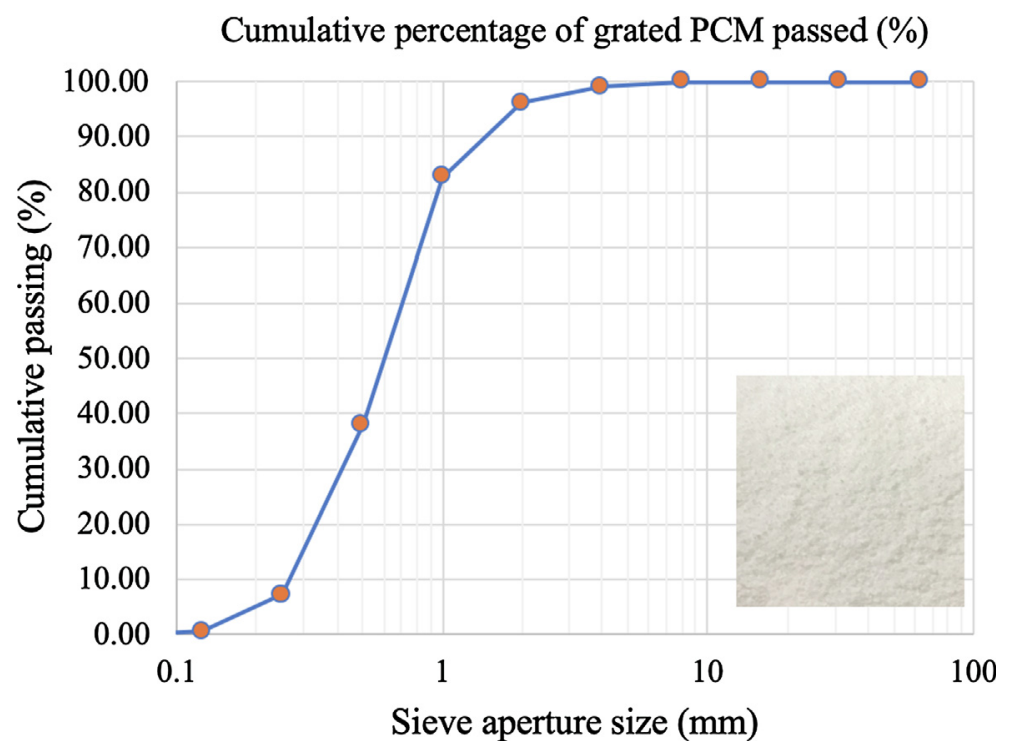

(f)

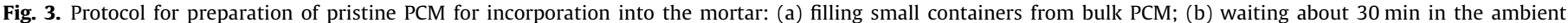

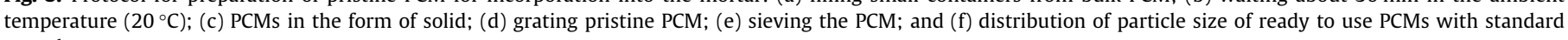
granulometry curve.

mixing of dry solid materials including sand, grated PCM and cement into a mixer for $30 \mathrm{~s}$ is carried out. Afterwards, adding water over the next $30 \mathrm{~s}$, and continue the mixing process for an additional $150 \mathrm{~s}$, stopping twice the mixing process to remove material from the mixer walls. Right after, the fresh mortar was cast into the moulds with respect to the type of the tests. The mortars were transferred to the steel moulds to produce specimens for future mechanical testing. Mortar casting for the thermal tests took place inside a climatic chamber with a constant temperature of $20^{\circ} \mathrm{C}$ and relative humidity $\mathrm{RH}=50 \%$; data acquisition was started at the end of the casting operations. After $24 \mathrm{~h}$, the specimens for the mechanical tests were demoulded. It should be mentioned that, for the production of the macro PCM capsule core, an aluminium foil (as a high conductive material) was used with a wall thicknesses about $1.6 \mathrm{~mm}$ in order to host the grated PCM in the shape of a macro capsule core PCM.
Specific nomenclature has also been given to the mixtures with macro capsule core of PCM in which "MPCMM10" stands for mortar with a cubicle macro capsule core filled with $10 \%$ Vol. of pristine PCM and "MPCMM20" stands for mortar with a cubicle macro capsule core filled with $20 \%$ Vol. of pristine PCM. It should be mentioned that, the volume size of the cubicle macro capsule cores for the formulations of MPCMM10 and MPCMM20 are the same ratios in terms of volume of grated PCM incorporation in the GPCMM10 and GPCMM20, respectively.

\subsection{Characterization of mortars}

Several experimental tests here was conducted to determine the thermo-physical properties of the studied mixture specimens in order to benchmark such properties related to the physical, mechanical and thermal properties of the mortars for use in the numerical simulations. 


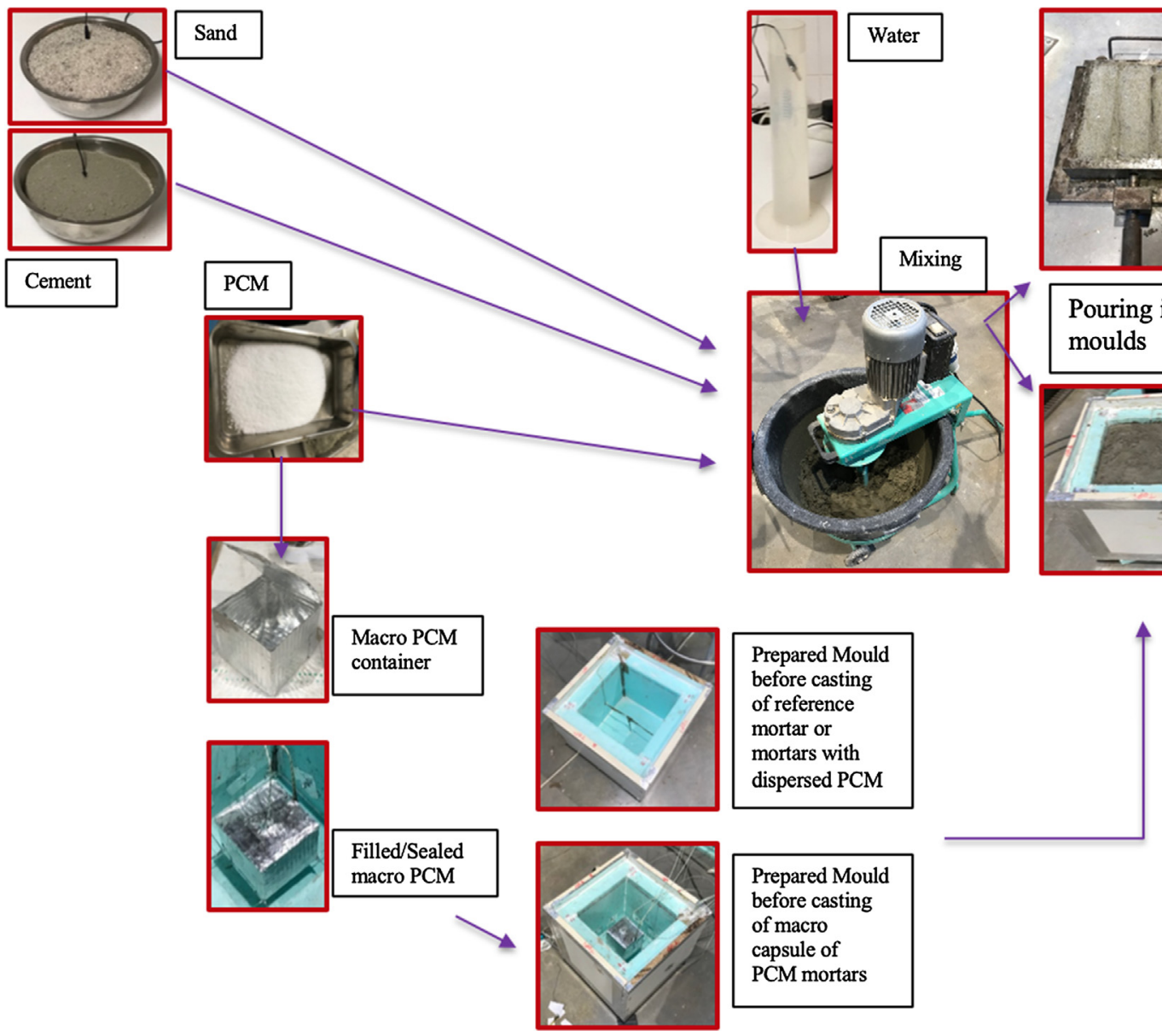

Fig. 4. Preparation procedures of specimens with grated PCM and macro capsule core PCM.

\subsubsection{Density}

For the density measurement, three specimens of each type were considered for each type of mixture. The test was following recommendations of EN1015:10 [26]. Firstly, the specimens were casted into prism moulds (with dimensions of $160 \mathrm{~mm} \times 40 \mathrm{~mm} \times 40 \mathrm{~mm}$ ). Then, the specimens were kept sealed with a plastic wrap at room temperature $\left(20 \pm 1^{\circ} \mathrm{C}\right)$ for $24 \mathrm{~h}$. Then, the specimens were submerged at $20 \pm 1^{\circ} \mathrm{C}$ for 7 days. Then, the specimens were dried at $70^{\circ} \mathrm{C}$ until recording constant weight for each specimen. The dimensions of the specimens were measured using a digital calliper with a precision of $0.02 \mathrm{~mm}$, and their weights were measured using an analytical balance with a precision of $0.001 \mathrm{gr}$. Density values for REFM, GPCMM10 and GPCMM20 were $2188 \mathrm{~kg} / \mathrm{m}^{3}, 1904 \mathrm{~kg} / \mathrm{m}^{3}$ and $1870 \mathrm{~kg} / \mathrm{m}^{3}$, respectively. Regarding the density difference between REFM, GPCMM10 and GPCMM20, it is interesting to note that the density of GPCMM 10 and GPCMM 20 are about $87 \%$ and $83 \%$ of that of REFM. In fact, the reduction of density for PCM mixtures were expected in view of the relevance of PCMs in the mixture which have lower densities than the sand particles.

\subsubsection{Thermal conductivity}

The thermal conductivity of the specimens was determined in three representative specimens for each mixture formulation. The measurements were carried out through a steady state heat flow meter apparatus (Mathis, model TCi), according to ISO8301:1991 [27]. Mixtures were casted into prism moulds with dimensions of $40 \times 40 \times 80\left(\mathrm{~mm}^{3}\right)$, which were sealed and cured for 28 days at $20^{\circ} \mathrm{C}$. The apparatus is based on the modified transient plane source technique for measurement of thermal conduc- tivity. It uses a one-sided, interfacial, heat reflectance sensor that applies a momentary, constant heat source to the specimen. The observed thermal conductivity of specimens GPCMM10 $(0.4 \mathrm{~W} / \mathrm{m} \mathrm{K})$ and GPCMM20 $(0.3 \mathrm{~W} / \mathrm{m} \mathrm{K})$, were significantly lower than that of REFM $(0.5 \mathrm{~W} / \mathrm{m} \mathrm{K})$. In fact, the PCM acts as insulating thermal material.

\subsubsection{Compressive strength}

The compressive strength tests were performed to evaluate the effect of the PCM on the mechanical strength of the mortars. First, a series of the specimens were deployed for each mix in which three specimens were tested at the proposed ages of testing $(7,14$ and 28 days) at room temperature $\left(20^{\circ} \mathrm{C}\right)$. The testing recommendations of EN1015-11 [28] were followed. All the specimens were kept sealed in a plastic wrap under at laboratory environment until testing date of 7, 14 and 28 days. Then, the compressive strength tests were carried out using apparatus model SHIMADZU-AG-IC with the capacity of $100 \mathrm{kN}$. For the compressive strength measurement, three specimens were considered for each type of the mortar and average values are reported.

Fig. 5 shows the compressive strength values in different specimens. The PCM incorporated in the mortar, as expected, reduces the compressive strength. The compressive strength of the GPCMM10 specimen in compare with REFM at 28 days is reduced by $18.6 \%$. Such trend is in the line with the literature: [29-31]. For all specimens, the average 28 days are $21.2 \%, 24.3 \%$ and $26.5 \%$ higher than the average 7 days, for REFM, GPCMM10 and GPCMM20 specimens, respectively. The strength of the GPCMM20 was reduced about $50 \%$ in comparison with REFM specimen. The replacement of $20 \%$ of sand volume significantly reduces the 
strength of the mortar. The compressive strength of GPCMM10 at 28 days attained about $32 \mathrm{MPa}$ that is still a reasonable value for the use in structural applications [32].

\subsubsection{Flexural strength}

Flexural strength testing was performed at ages of 7, 14 and 28 days following the standard EN1015-11 [28]. Three prism specimens with dimensions of $40 \times 40 \times 160\left(\mathrm{~mm}^{3}\right)$ were prepared and sealed by plastic wrap in room temperature $\left(20^{\circ} \mathrm{C}\right)$ until testing. A three-point loading method was deployed using apparatus model SHIMADZU-AG-IC with the capacity of $100 \mathrm{kN}$. For the flexural strength measurements, three specimens were considered for each type of mixture and average values are reported. The trend of the flexural strength is similar to the observed for the compressive strength (see Fig. 6). The flexural strength of $6 \mathrm{MPa}$ was measured for GPCMM10 and 4.5 MPa for GPCMM20 at 28 days. The addition of PCM also resulted in the reduction of the flexural strength. The flexural strength at 28 days for specimens GPCMM10 and GPCMM20 is significantly reduced in comparing with REFM by $23.8 \%$ and $42 \%$, respectively. Similar behaviour was observed in previous studies by other authors: [11,33-35].

\subsection{Design and fabrication of the cube specimens}

In order to assess the effect of different type of incorporating methods and quantities of PCM into mortar, for measuring early age temperature, five cube specimens were casted. The geometry of the cubes for the testing of REFM, GPCMM10 and GPCMM20 specimens, whose dimensions are $200 \times 200 \times 200 \mathrm{~mm}^{3}$, is presented in Fig. 7. Lateral faces, base and top of the element were

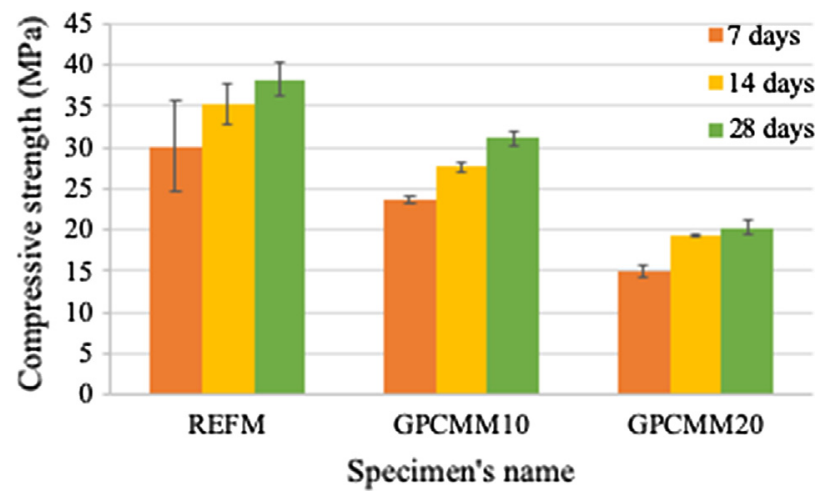

Fig. 5. Compressive strength of mixture specimens for different curing time (for each mortar type, three specimens were tested and the average and standard deviation of the measured values are shown).

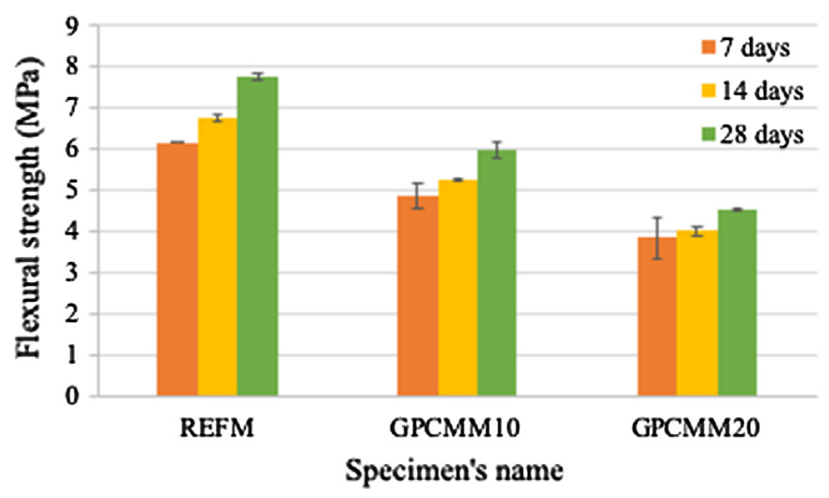

Fig. 6. Flexural strength of mixture specimens for different curing time (for each type of mortar, three specimens were tested and the average and standard deviation of the measured values are shown). insulated with $40 \mathrm{~mm}$ thick extruded polystyrene (XPS) and $20 \mathrm{~mm}$ thick plywood formworks. For the PCM macro capsule core specimens, MPCMM10 and MPCMM20, an aluminium container (with high thermal conductivity) was used to host the pristine PCM with interior dimension of $75 \mathrm{~mm}^{3}$ and $92 \mathrm{~mm}^{3}$ for cases MPCMM10 and MPCMM20 specimens, respectively. For the sake of brevity, only schematic representation of the experimental set up for macro capsule core PCM mixture (MPCMM10) presented in Fig. 8. Mixture casting and the experimental procedures took place inside a controlled climatic chamber with a constant temperature of $20^{\circ} \mathrm{C}$ and relative humidity of $50 \%$. Data acquisition started at the end of the casting operations.

Regarding the experimental monitoring equipment, temperature sensors type $\mathrm{K}$ (thermocouple) very easy to use and economical, with precision of $\pm 1.1^{\circ} \mathrm{C}$, were placed at different locations: geometrical centre of the mortar, exterior surface (level of mid height), and the edge at different height of the mortar: (i) on the top corner level; (ii) on the mid corner level; (iii) on the bottom corner level, between plywood formwork and XPS layer, and exterior surface of the plywood formwork. It should be mentioned that, in the cases of macro capsule core PCM mortars, one sensor was placed at the geometrical centre of the aluminium container, and one on the interior wall and another on the exterior wall. In fact, an identical temperature profile is expected in the symmetrical position for the purpose of comparison of measurements. Sensor locations are schematically presented in Figs. 7 and 8. These nomenclatures of top corner of the mortar cube (TC), mid corner of the mortar cube (MC), bottom corner of the mortar cube (BC), mid height of exterior boundary of plywood formwork (M1), mid height between plywood formwork and XPS (M2), mid height between XPS and mortar (M3), mid height centre of mortar cube (MM), mid height exterior boundary wall of aluminium container (M4), mid height interior boundary wall of aluminium container (M5), and mid height centre of pristine PCM inside aluminium container (MP), will also be adopted in this paper, for the discussion of results.

A total of five experiments were conducted by submitting the specimens to the controlled climatic chamber with experiment lasting 4 days. The temperature sensor reading in the different locations of the specimens were collected through a computer based data acquisition system (AGILENT 34970A) with a rate of one measurement per $15 \mathrm{~min}$, during the whole 4 days period of testing. The physical arrangement of this setup can be observed in the pictures shown in Fig. 9. In this figure it is also visible, the use of a "supporting mesh" below the cube specimens in order to ensure that heat losses through the bottom surface would be similar to those of the other surfaces (hence guaranteeing symmetry).

\subsection{Thermal performance of cube specimens}

Temperature measured in the position BC, MC, TC and M3 of the REFM, GPCMM10 and GPCMM20 specimens are presented in Fig. 10. It can also be noted that, the temperature rise period begins after mortar casting and lasts for about one day, then, followed by the cooling down period that goes on until the fourth day, reaching thermal equilibrium between the mortar specimen and the climatic chamber environment. It can be noticed that sensors located at points $\mathrm{BC}, \mathrm{MC}, \mathrm{TC}$ and $\mathrm{M} 3$ recorded the peak temperatures for different ages for the cases of GPCMM10 and GPCMM20 when compared with REFM. As expected, the sensors in the mortar specimens containing more PCM content, have recorded lower temperatures regardless of the sensor location and slightly shifted towards the left (i.e. delayed in time). Furthermore, it is worth noting that mixtures containing PCM reveal the charging and discharging effects in phase change within the temperature range 


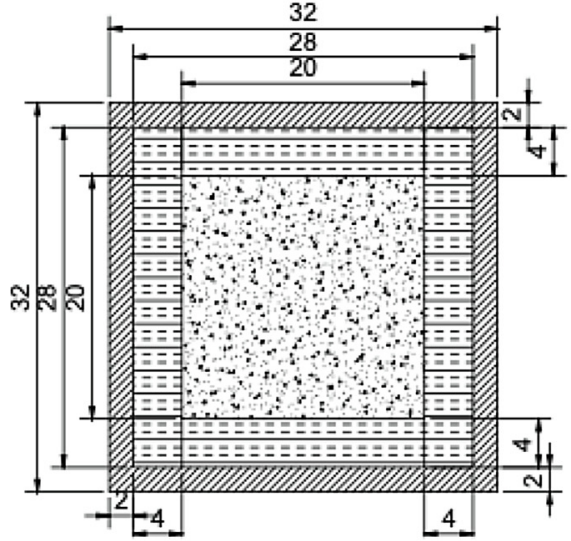

(a) Plan/Top view

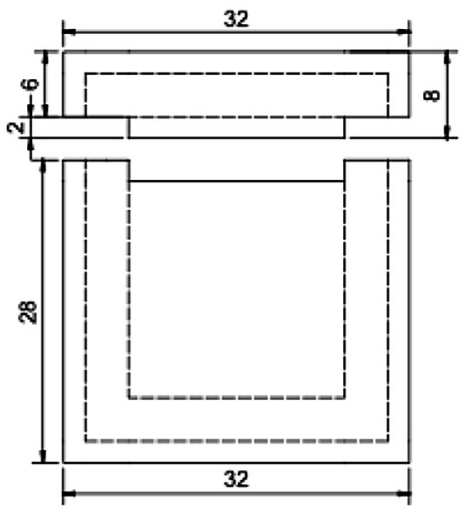

(c) Front view

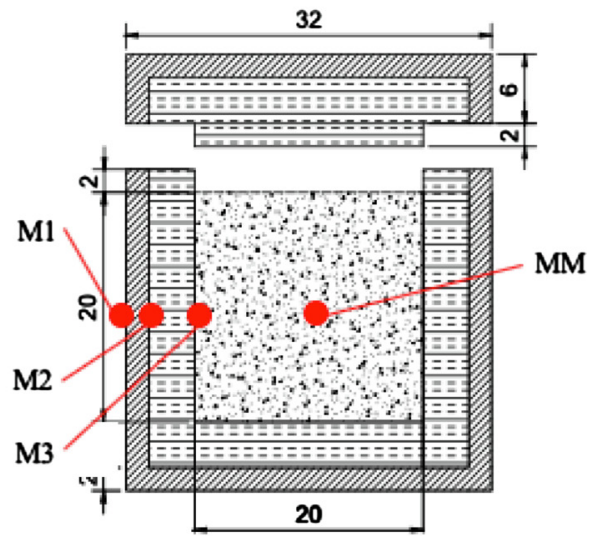

(b) Cross section

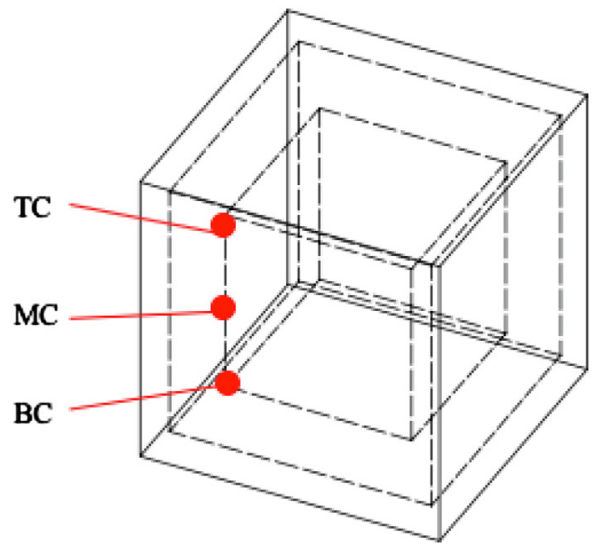

(d) 3D view

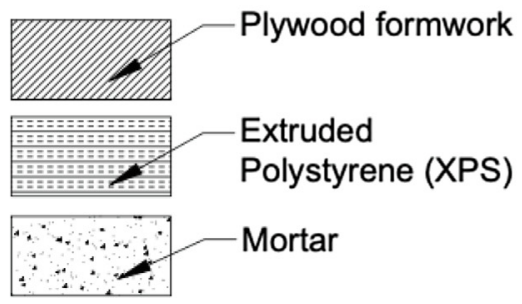

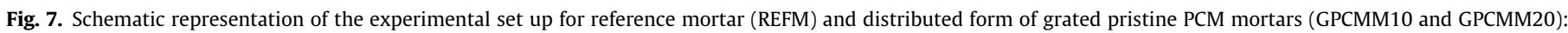
mixtures and sensor locations (labelled as “○”). Units [cm].

$33-36{ }^{\circ} \mathrm{C}$, both during ascending and descending branches of the temperature plots.

In the cases of GPCMM10 and GPCMM20 the maximum peak temperature reduction was recorded at point TC by $\sim 5^{\circ} \mathrm{C}$ and $\sim 9{ }^{\circ} \mathrm{C}$ when compared with REFM, respectively (see Fig. 11).

Fig. 12 shows comparison of temperature profiles between cases of MPCMM10 and MPCMM20. The observations are quite similar to those already stated for GPCMM10 and GPCMM20 mortar specimens.

It can be noticed that sensors at points BC, MC, TC and M3 always measured peak temperature delay in the case of MPCMM20 in comparison with MPCMM10, opposed to those that were observed for the cases with PCM in the dispersed form (see Fig. 12). The maximum and minimum peak temperature differences between MPCMM10 and MPCMM20 were of $3.9^{\circ} \mathrm{C}$ and $2.4^{\circ} \mathrm{C}$ at BC and TC sensor points, respectively (see Fig. 13).
Generally, it can be observed that the PCM always leads to the temperature profile attenuation. The temperature profile at e.g. control point (M3) for the two methods of PCM incorporation that were assessed, have revealed to effectively reduce the peak temperature. However, the type of incorporation of PCM into the mixture is very effective in term of surface temperature profile evolution during early ages (in particular differences in rising temperature ramp of MPCMM20 and GPCMM20 is clearly noticeable). However, the temperature rise for all PCM cube specimens resemble the same attenuation and delay trend, as shown in Figs. 10 and 12.

Fig. 14 shows measurements from the thermocouples placed along different layers of the specimens in the middle height level. It can be observed that, the surface temperature of the specimen (M1) is almost constant for all cases due to the set point considered for climatic chamber as of $20^{\circ} \mathrm{C}$. Temperature monitoring between 


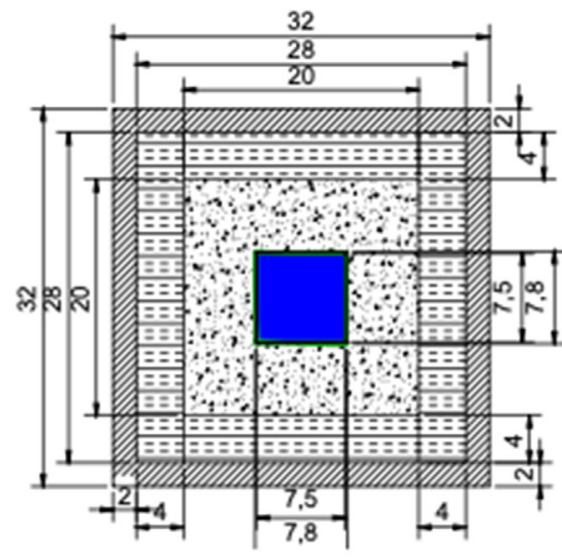

(a) Plan/Top view

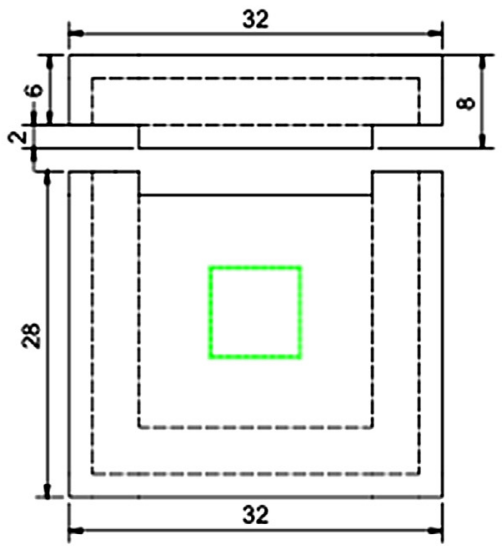

(c) Front view

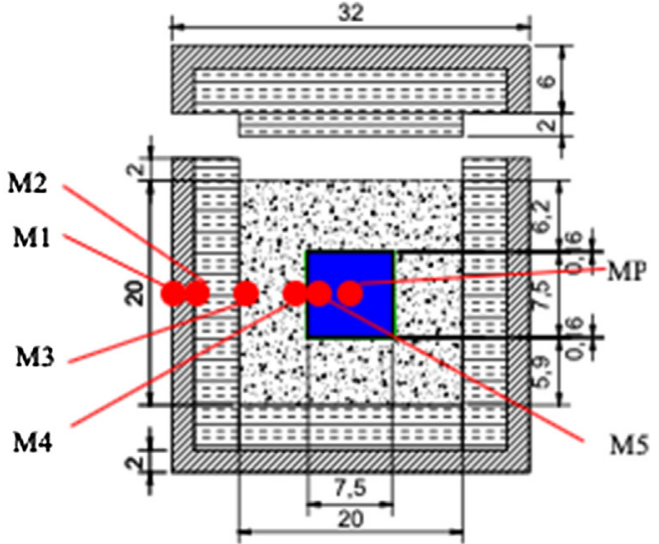

(b) Cross section

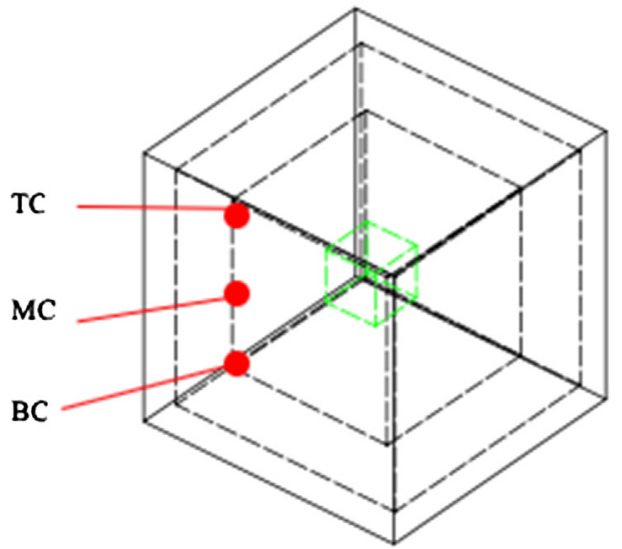

(d) 3D view

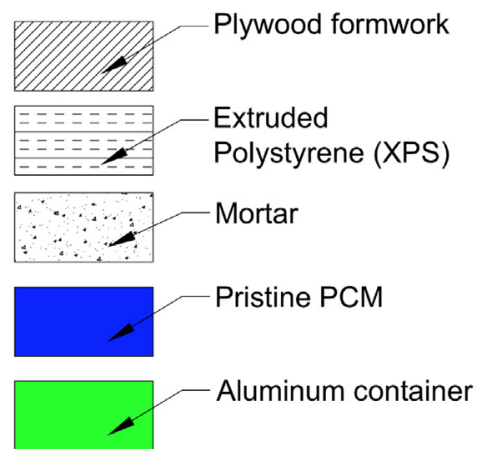

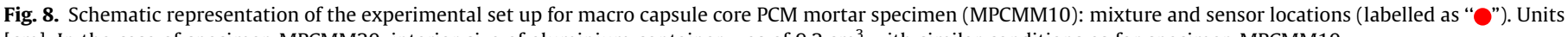
$[\mathrm{cm}]$. In the case of specimen MPCMM20, interior size of aluminium container was of $9.2 \mathrm{~cm}^{3}$ with similar conditions as for specimen MPCMM10.

plywood formwork and XPS (M2) indicated the influences of the thermal insulation around cubic mortars experienced lower temperature (below $25^{\circ} \mathrm{C}$ ) for different studied cases. It is worth noting the strong coherence of temperatures measured by the thermocouples positioned at M3 and MM for the cases of GPCMM10, GPCMM20 and REFM. In fact, the placement of these thermocouples is along two symmetrical plans of the mixture element for REFM, GPCMM10 and GPCMM20. In the cases of MPCMM10 and MPCMM20, the monitored temperatures at intersection of the symmetrical plans (MP) shows the flatter effectiveness of the PCM due to it is specific heat capacity of the PCM. Measured temperatures at M4 and M5 in cases of MPCMM10 and PCMM20 are also coherence confirming the material used for
PCM container had no effect on the heat transfer between aluminium container and mixture. However, there is slight disturbance observed in the case of MPCMM20.

\section{Numerical simulation}

\subsection{Governing equations}

The general transient heat conduction equation [36] was applied for the numerical simulation of the heat transfer processes in the studied models:

$k \nabla \cdot(\nabla T)+\dot{Q}=\rho C \dot{T}$ 


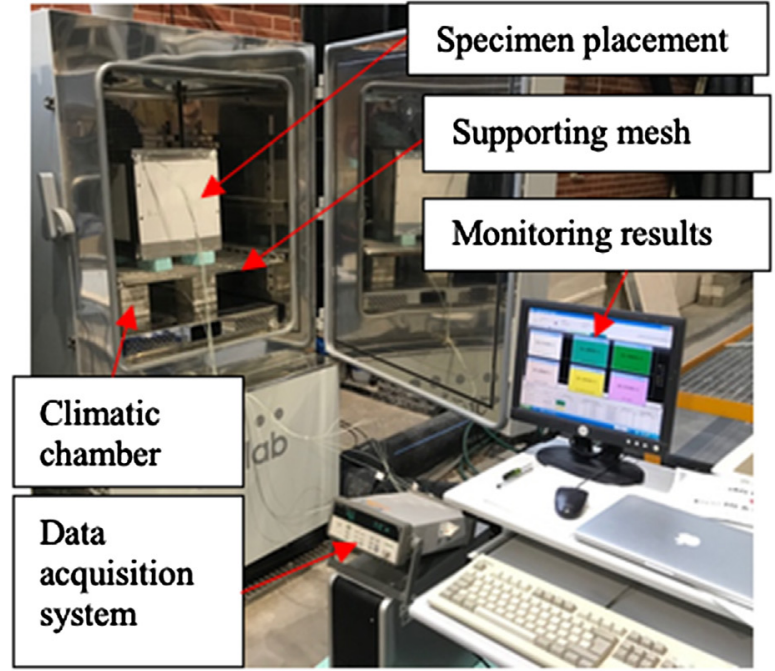

(a)

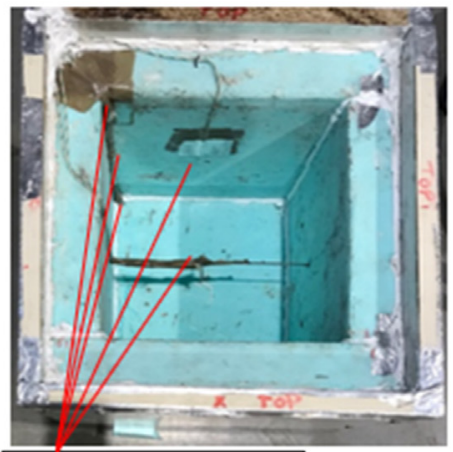

Sensors placement before casting

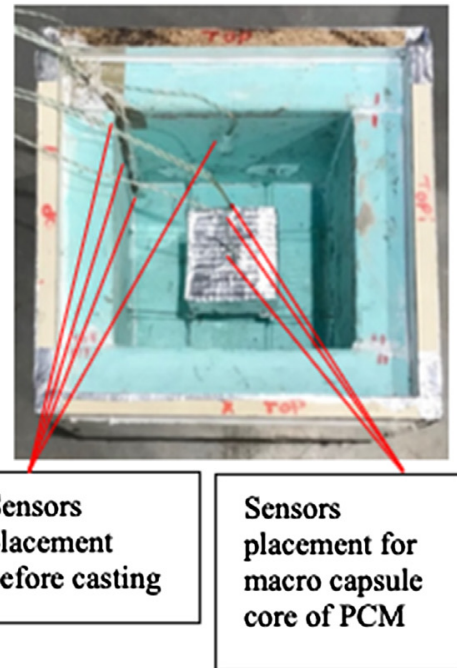

(c)

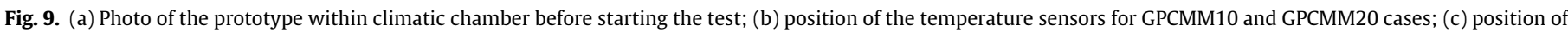
the temperature sensors for MPCMM10 and MPCMM20 cases.

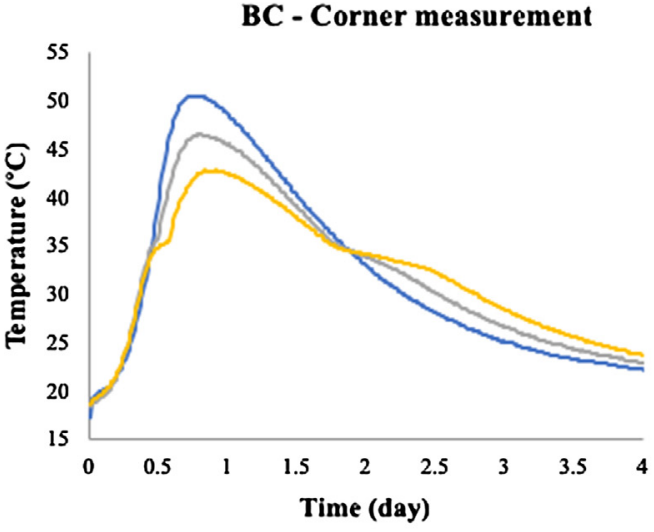

(a)

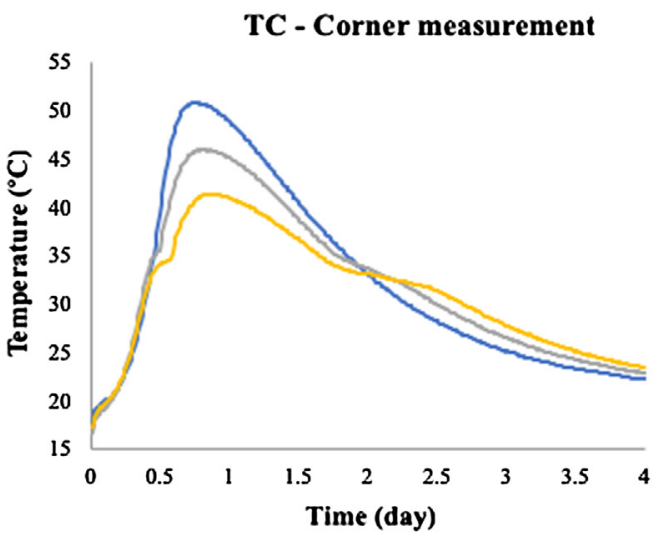

(c)

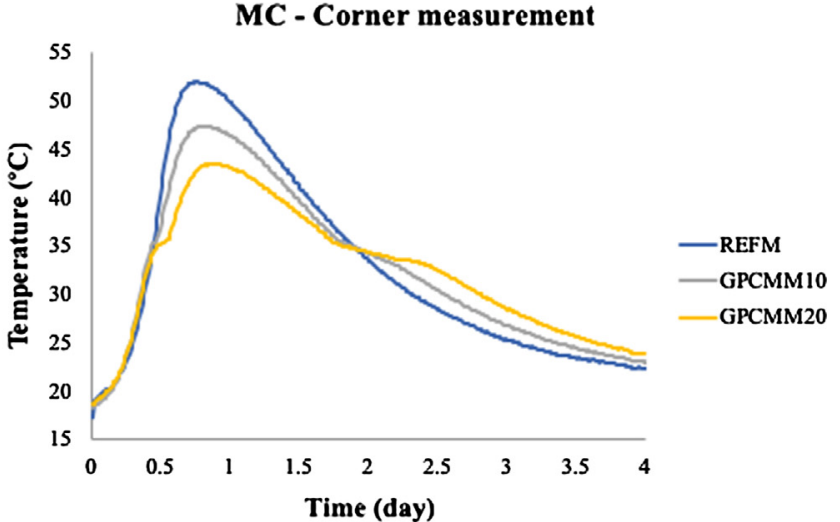

(b)

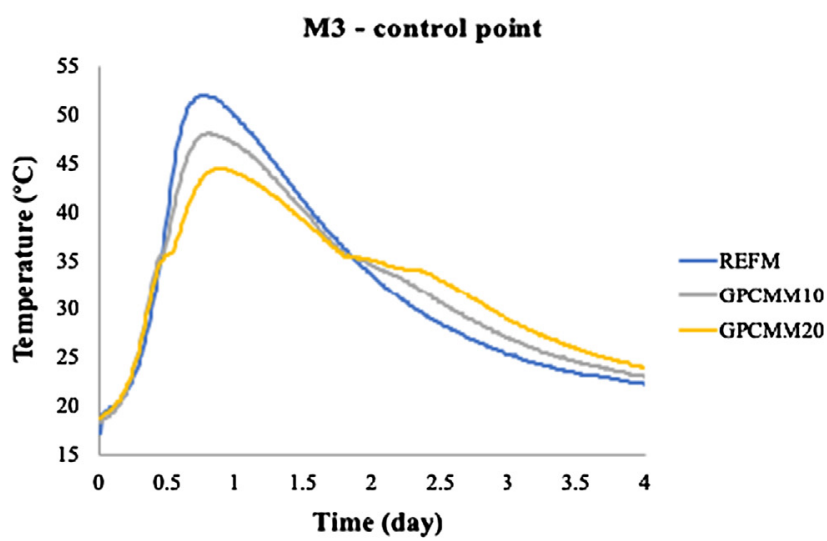

(d)

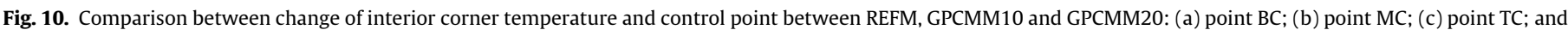
(d) M3 point. 


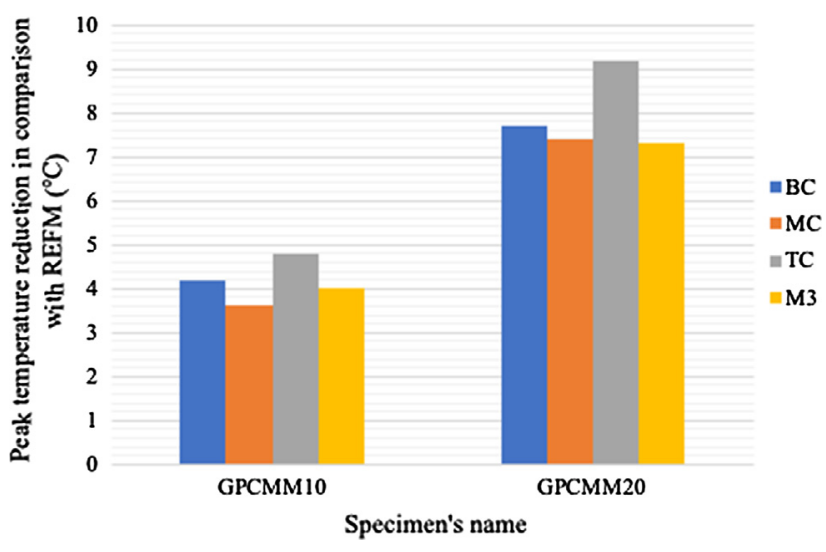

Fig. 11. Peak temperature reduction between reference mortar (REFM) and PCM mortars (GPCMM10 and GPCMM20) at BC, MC, TC and M3 positions.

where $Q$ is the rate of internal heat generation $\left(\mathrm{W} / \mathrm{m}^{3}\right)$ generated by cement hydration, $k$ is the thermal conductivity and $\rho$ Cis the volumetric specific heat $\left(\mathrm{J} / \mathrm{m}^{3} \mathrm{~K}\right)$ of the mortar. $Q$ plays a fundamental role on the thermal problem to be solved, and accordingly it should be determined on real characterization of the cement hydration heat production, considering activation energy phenomena (thermally-activated). As the same type of cement, from the same supplier had been tested and reported before [37] through isother- mal calorimetry testing (including evaluation of activation energy), the corresponding results have been used as input for the models of simulation of this paper. The simulation of the heat generation was made with basis on an Arrhenius law of the type [16]:

$\dot{Q}=a f(\alpha) e^{\frac{E_{a}}{R T}}$

where $E_{a}$ is the activation energy $(\mathrm{J} / \mathrm{mol}), R$ in the universal gas constant $(8.314 \mathrm{~J} / \mathrm{mol} \mathrm{K}), a$ is proportional to the maximum value of the heat production rate $\left(\mathrm{W} / \mathrm{m}^{3}\right)$ and $f(\alpha)$ is the evolution of normalized heat production rate. It is worth to mentioned that, the degree of heat development $\alpha$, in the numerical simulation definition is the level of completion of the release of cement hydration heat which, in the case communicated herein, evolves from 0.1 (at initiation of simulation, considering release of heat before placement into mould) up to 1 . The formulation of $Q$ assumes no chemical interaction between cement and the PCM. This assumption is deemed feasible, as no opposing trend was found in the literature on this subject.

In regard to boundary conditions applied to the temperature field computation based on Eq. (2), the corresponding heat flows are taken into account through a convective/radiative boundary flux, as shown in Eq. (4), where $T$ is the temperature $\left({ }^{\circ} \mathrm{C}\right), T_{s}$ is the surface temperature $\left({ }^{\circ} \mathrm{C}\right)$ and $h_{c r}$ a convection/radiation coefficient that depends on air speed $(\mathrm{W} / \mathrm{m} \mathrm{K})[16]$ :

$q=h_{c r}\left(T-T_{s}\right)$

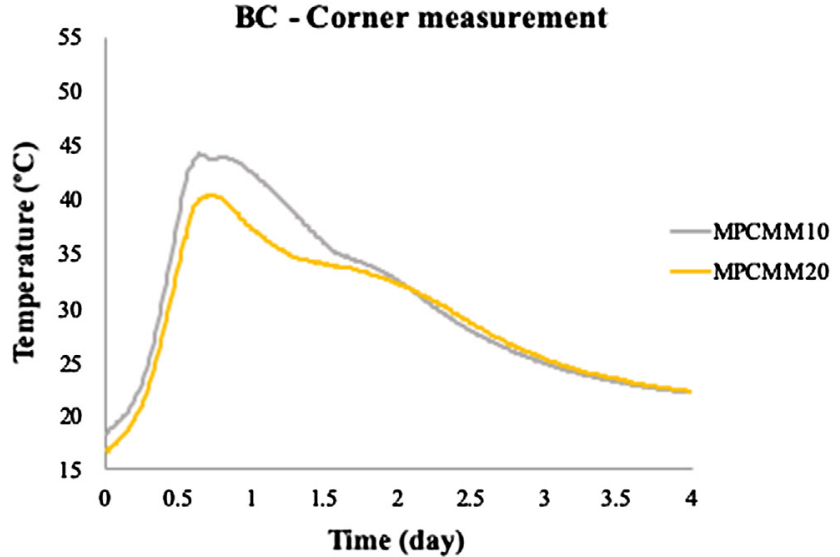

(a)

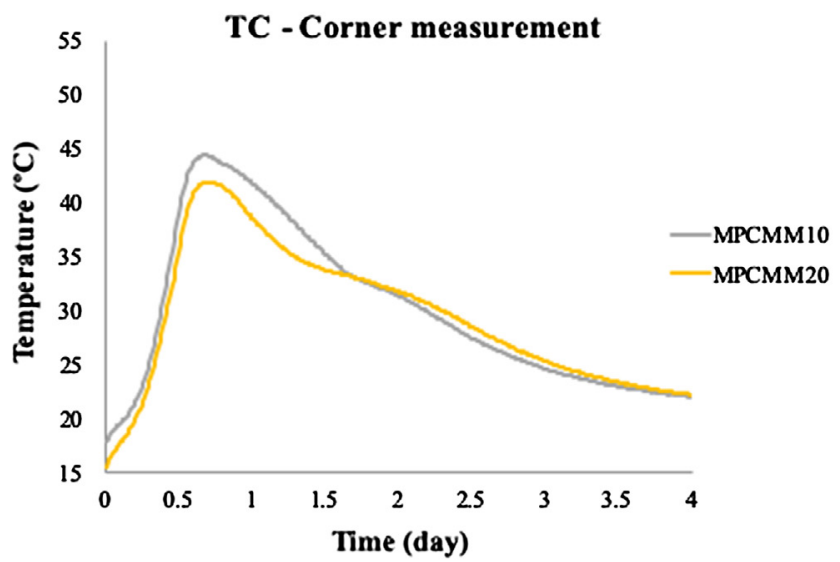

(c)

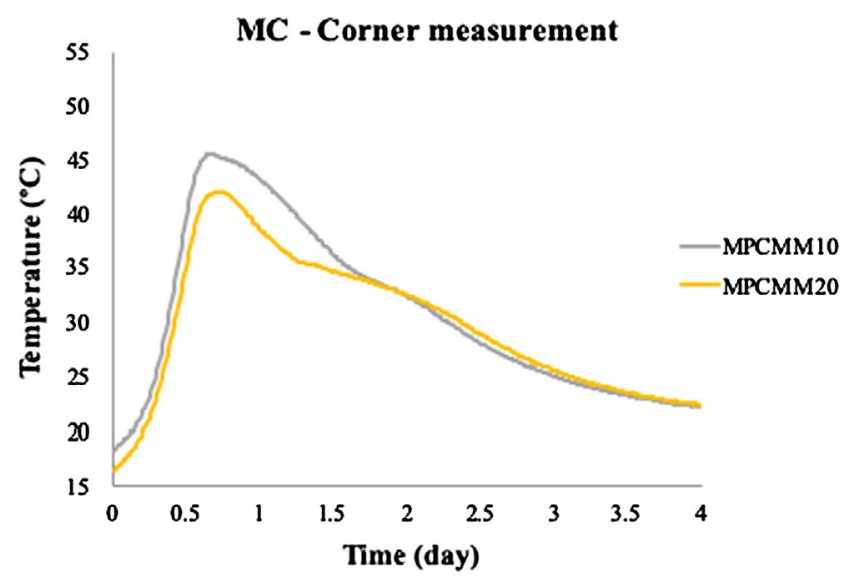

(b)

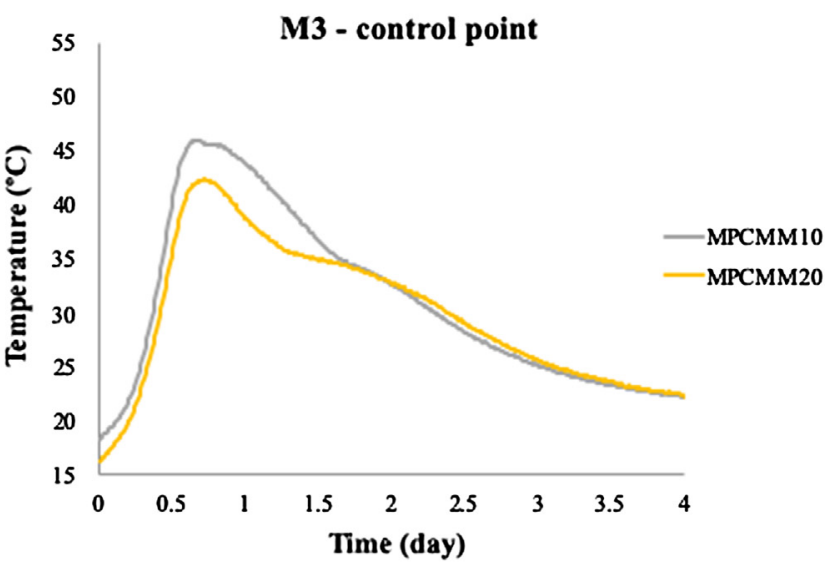

(d)

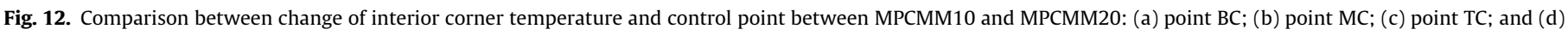
M3 point. 


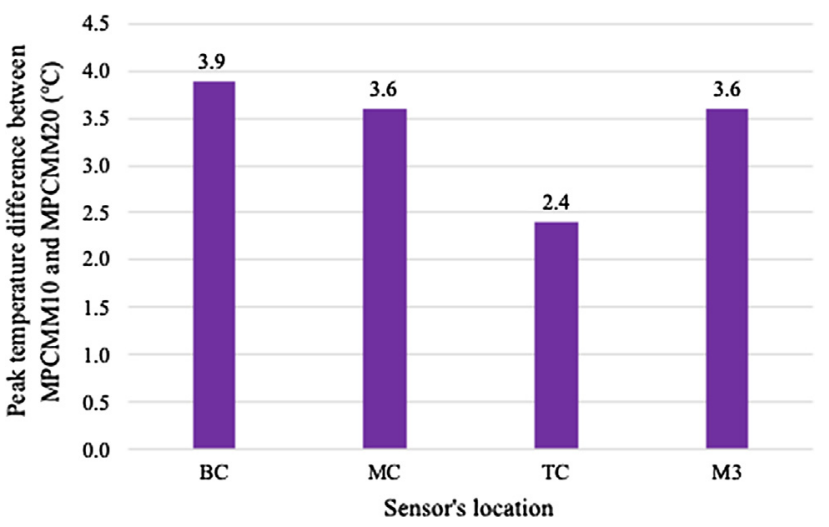

Fig. 13. Peak temperature differences between MPCMM10 and MPCMM20 at BC, MC, TC and M3 positions.

GPCMM10

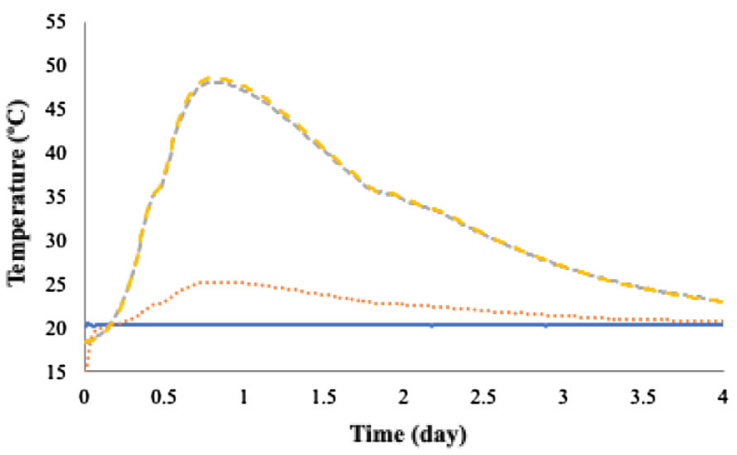

(a)

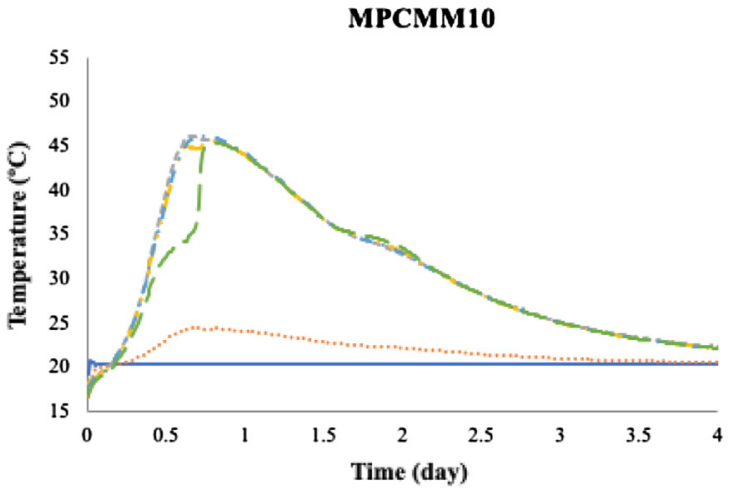

(c)

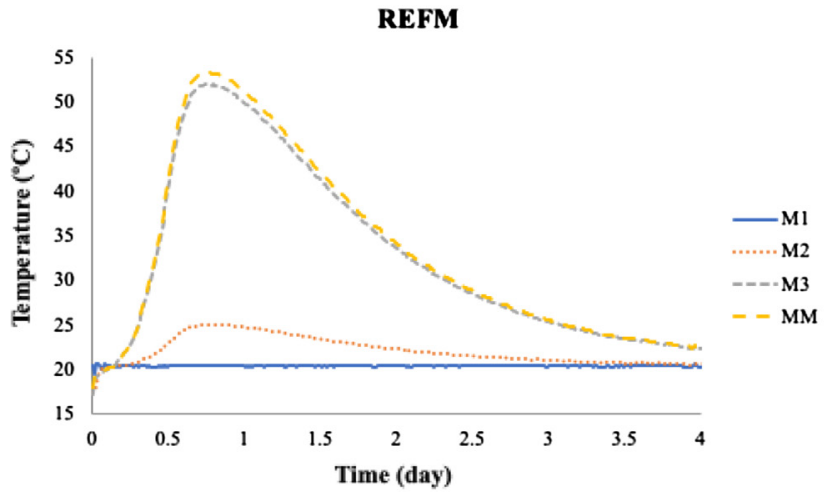

(e)

\subsection{Phase change modelling}

In the present work, and for the particular case in which PCM is distributed within the mortar mixture, the strategy for simulation of the enthalpy of phase change consists in increasing the heat capacity value of the mortar during the phase change process, which is normally termed as 'specific heat capacity method' $[38,39]$. In the experimental curve of specific heat capacity versus temperature (see Fig. 4), the sensible heat and latent heat temperature ranges are not precisely distinguishable, thus, the specific heat capacity method could be beneficial as allows observing such curve/behaviour regardless state of the PCM. Hence, the effects of the phase change in this case (PCM distributed within the mortar mixture - GPCMM10 and GPCMM20) were modelled through a simplified approach by which the energy release/absorption associated to the phase change process is considered through artifacts

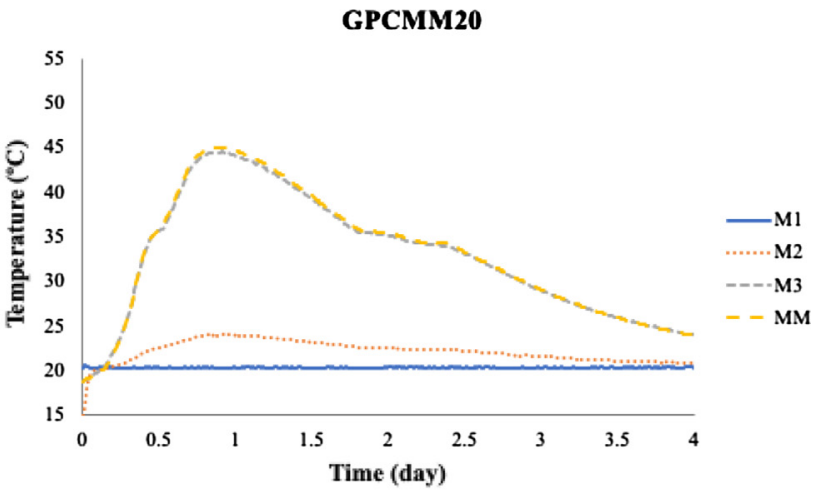

(b)

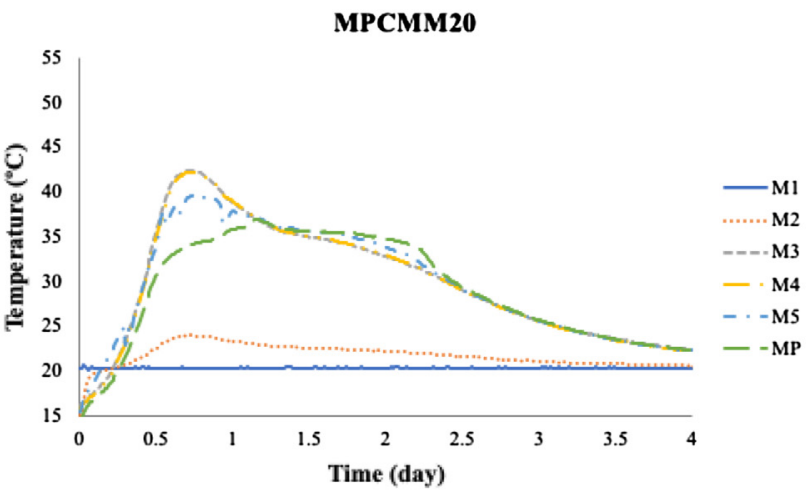

(d)

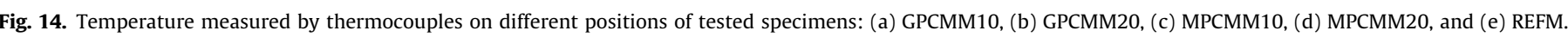




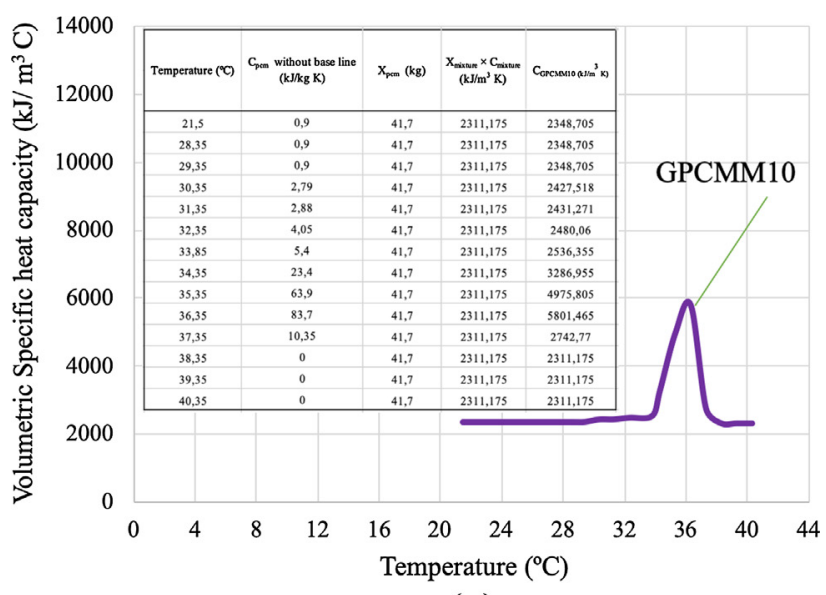

(a)

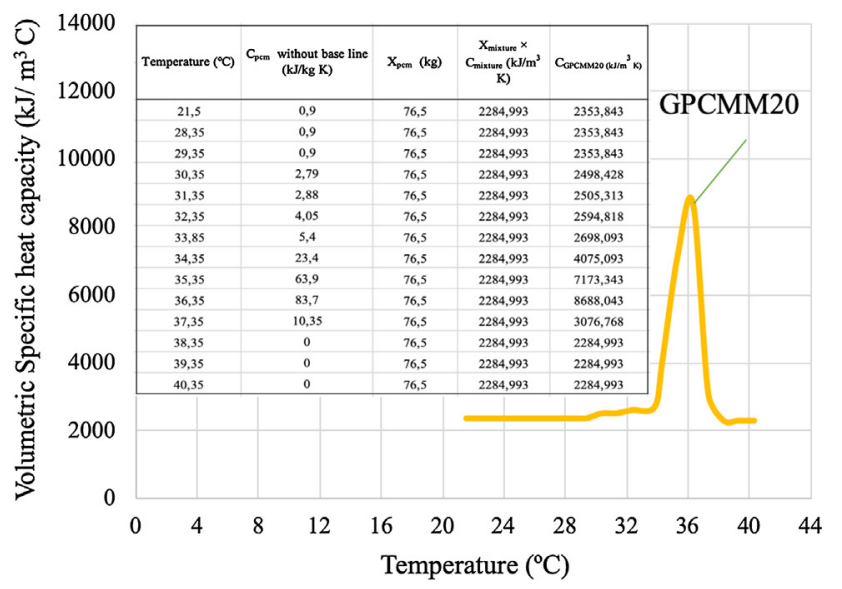

(b)

Fig. 15. Estimated specific heat capacity curves of the PCM mortars based on the experimental results obtained for pristine PCM (RT35HC): (a) for GPCMM10; and (b) for GPCMM20.

applied to the specific heat capacity term shown in Eq. (2). This approach consisted in making a proportionality estimation, based on a simple mixing law, in order to extrapolate the expectable specific heat of mortar, following equation Eq. (5) [17]:

$C_{\text {specimen }}(T)=\left(X_{\text {mixture }} \times C_{\text {mixture }}\right)+\left(X_{P C M} \times C_{P C M}\right)$

where $C_{\text {specimen }}$ is the specific heat capacity of the mortar mixture containing PCM $(\mathrm{kJ} / \mathrm{kg} \mathrm{K})$ as a function of temperature $(\mathrm{T}), X_{\text {mixture }}$ stands for mass fraction of the mortar mixture, $C_{\text {mixture }}$ is the specific heat capacity of the mortar mixture $(\mathrm{kJ} / \mathrm{kg} \mathrm{K}), X_{P C M}$ is mass fraction of the PCM within matrix, and $C_{P C M}$ is specific heat capacity of the PCM (as extracted directly from Fig. 4). The volumetric specific heat capacity for GPCMM10 and GPCMM20 was obtained by multiplying the previous result by the volumetric density of specimens are illustrated in Fig. 15 and ready for implementation in numerical simulation.

For the computation of the volumetric specific heat capacity of the macro capsule core PCM for the cases of MPCMM10 and

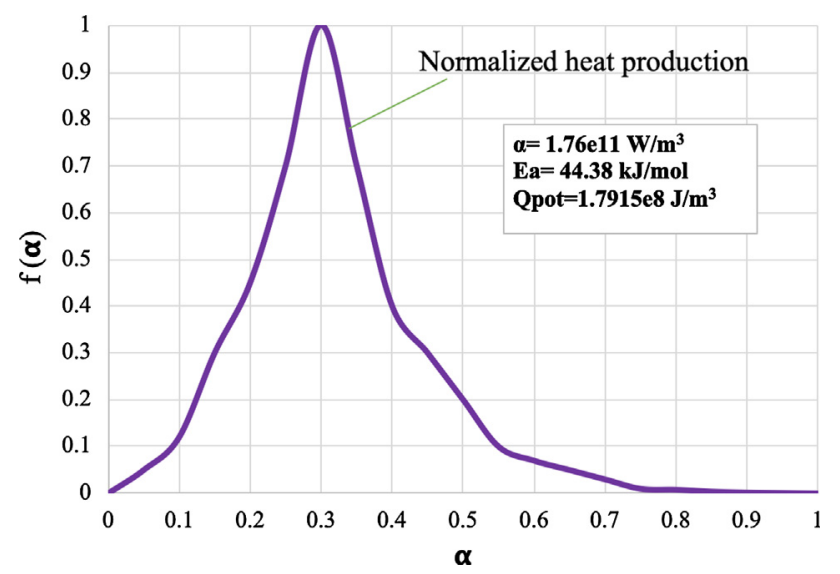

Fig. 17. Arrhenius law for the studied mixture.

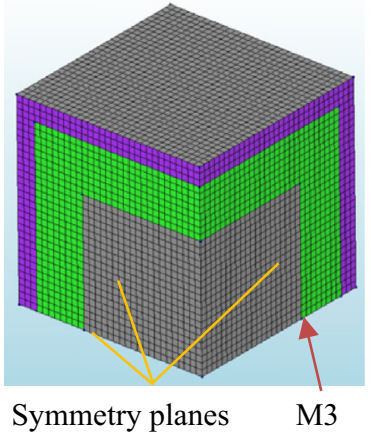

(a)

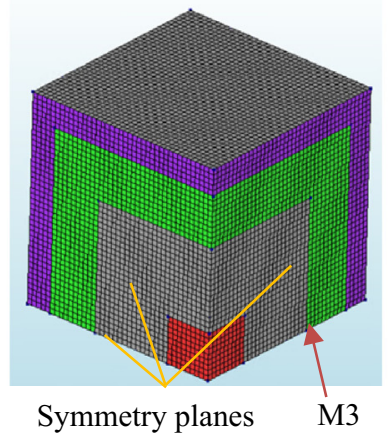

(b)

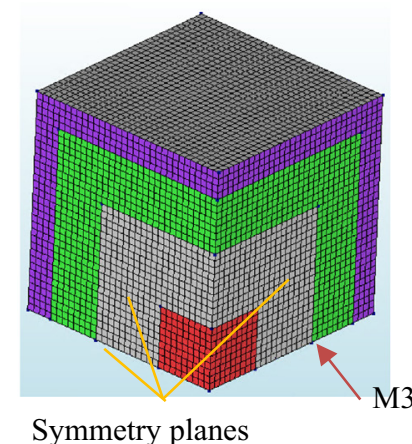

(c)

Fig. 16. The 3D model mesh for: (a) REFM, GPCMM10 or GPCMM20; (b) MPCMM10; (c) MPCMM20.

Table 2

Thermo-physical properties of the materials used in the numerical simulations.

\begin{tabular}{|c|c|c|c|c|c|c|c|}
\hline Thermo-physical properties & Units & REFM & GPCMM10 & GPCMM20 & XPS & Plywood & Pristine PCM \\
\hline Density & $\left(\mathrm{kg} / \mathrm{m}^{3}\right)$ & 2188 & 1904 & 1877 & 32 & 650 & 880 \\
\hline Thermal conductivity & $(\mathrm{W} / \mathrm{m} \mathrm{K})$ & 0.5 & 0.4 & 0.3 & 0.035 & 0.15 & 0.2 \\
\hline Volumetric Specific heat capacity & $\left(\mathrm{kJ} / \mathrm{m}^{3} \mathrm{C}\right)$ & 2189 & Fig. 15a & Fig. 15b & 44.8 & 854.4 & Fig. 2 \\
\hline
\end{tabular}




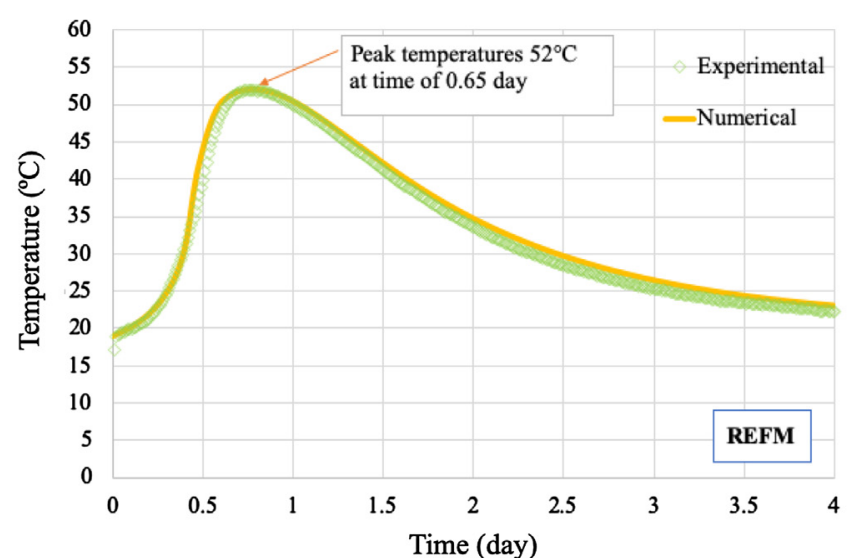

(a)

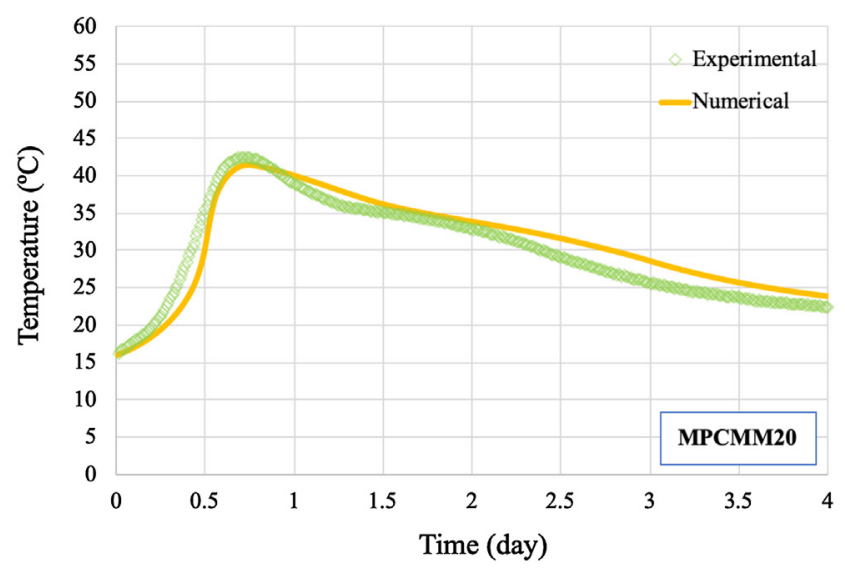

(c)

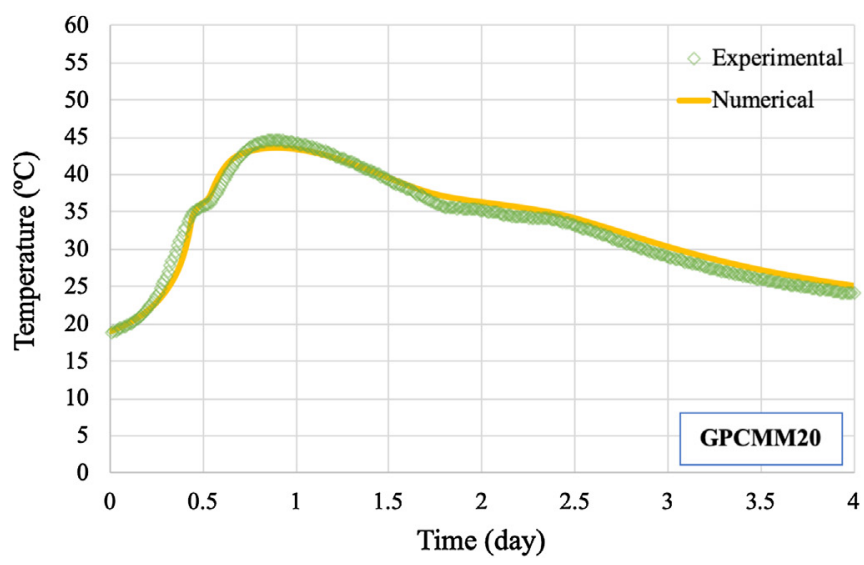

(e)

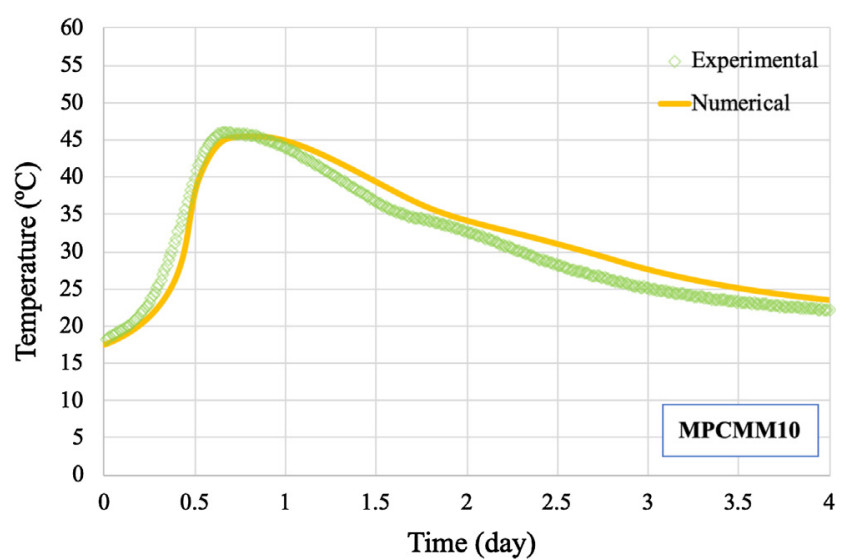

(b)

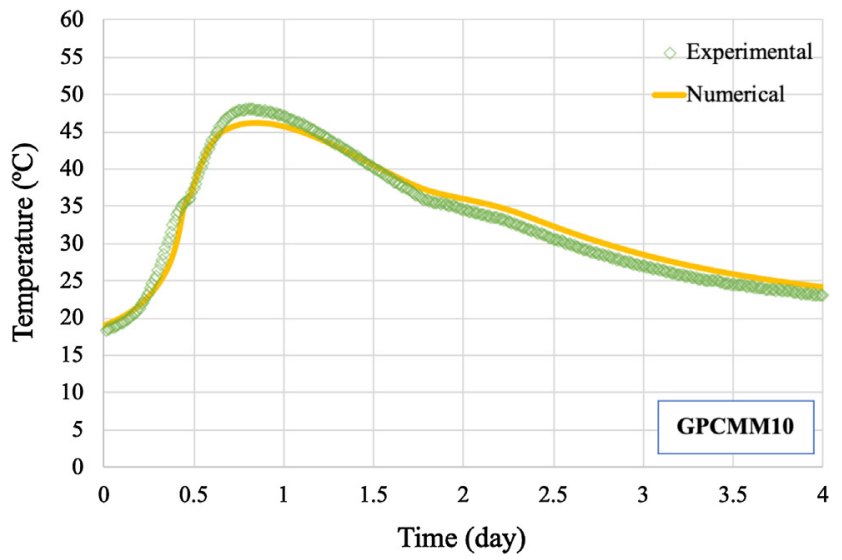

(d)

Fig. 18. Experimental versus numerical values for different models at control point (M3): (a) REFM; (b) MPCMM10; (c) MPCMM20; (d) GPCMM10; and (e) GPCMM20.

MPCMM20, the information of Fig. 4 was used directly for model input of the specific heat of the material, for application in Eq. (2).

\subsection{Modelling geometry and parameters}

The five cases presented in Section 2 were simulated: (i) REFM; (ii) GPCMM10; (iii) GPCMM20; (iv) MPCMM10; and (v) MPCMM20. The specimen with exterior dimensions of $32 \times 32 \times 32 \mathrm{~cm}^{3}$ has been considered. Since there are three vertical symmetry plans, only one-eighth of the prototype with dimensions of $16 \times 16 \times 16 \mathrm{~cm}^{3}$ was modelled. It is noted that it was decided to explicitly model the XPS and formwork linings around the specimen due to the fact that they ended up storing some heat in the experiment (due to their relatively significant thickness in regard to the mortar specimen inside). The generated finite element mesh (eight noted isoperimetric finite element), is depicted in Fig. 16a-c. In the adopted 3D discretization finite elements renders element size of $0.05 \mathrm{~cm}$ for the cases of REFM, GPCMM10, GPCMM20 and MPCMM20, while, a quite refined mesh in the MPCMM10 with element size of $0.04 \mathrm{~cm}$ used. In the symmetry plans, adiabatic boundaries were considered. 
(a)

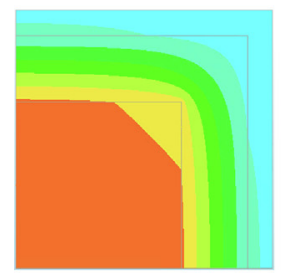

(b)

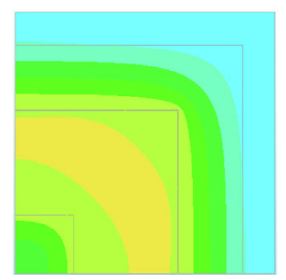

(c)

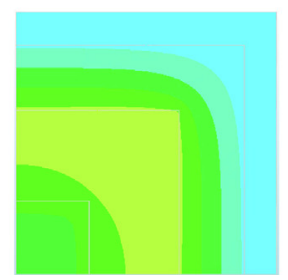

(d)

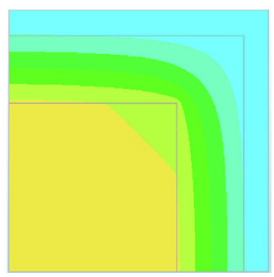

(e)

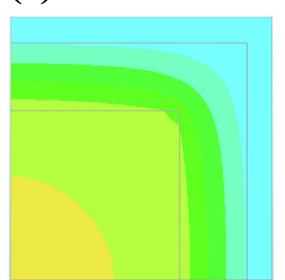

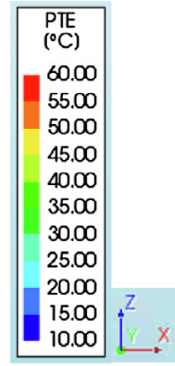

Temperature field

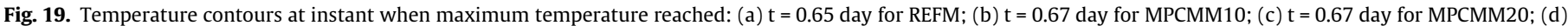
$\mathrm{t}=0.8$ day for GPCMM10; and (e) $\mathrm{t}=0.8$ day for GPCMM20, under proposed environmental condition.

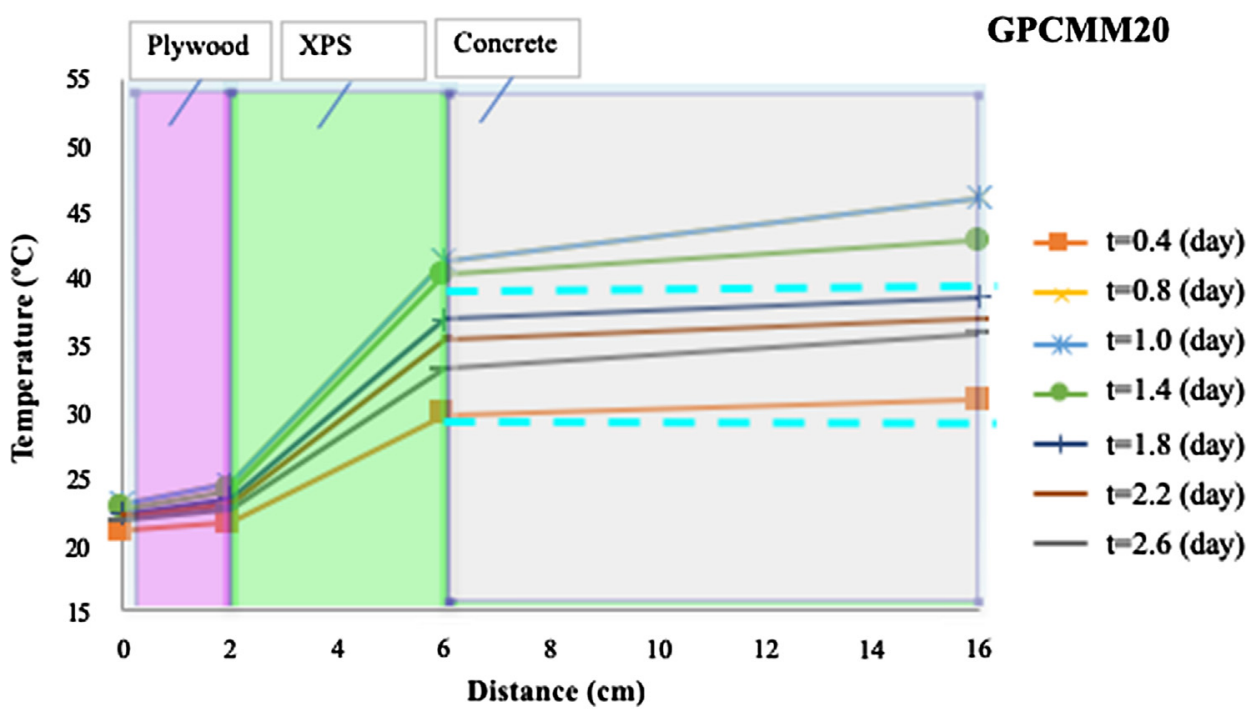

(a)

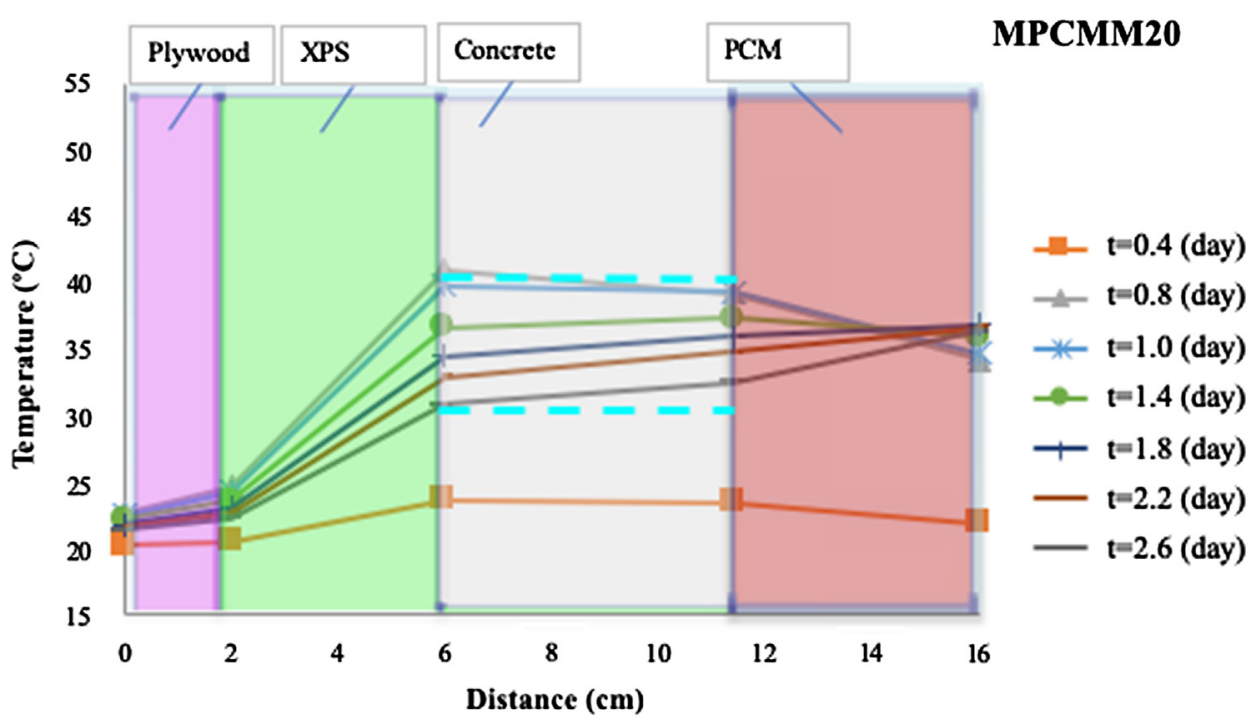

(b)

Fig. 20. Temperature variations along the thickness of the wall of cube specimens at different hours: (a) GPCMM20; and (b) MPCMM20.

The main thermo-physical properties of all materials used in the simulations of REFM, GPCMM10, GPCMM20, MPCMM10 and MPCMM20 are synthetized on Table 2 and detailed next. This table also contains information about the materials that were used in the construction of the mould walls. It is noted that the specific heat capacity of mixture containing distributed PCM was estimated 
based on Eq. (6). It should be mentioned that, the characteristics of the MPCMM10 and MCPMM20 for simulation inputs are composed of the REFM and pristine PCM.

In regard to the boundary conditions applied to the temperature field computation, for the surfaces in contact with wooden framework panels, $h_{c r}$ was of $5 \mathrm{Wm}^{-1} \mathrm{~K}^{-1}$. In the symmetry plans adiabatic condition were applied. A constant time step size of $300 \mathrm{~s}$ and number of time steps of 1152 were considered (4 days). The convergence criteria at each time step was checked under $10^{-5}$ for energy equation.

The initial temperature for the cases of REFM, GPCMM10, GPCMM20, MCPMM10 and MPCMM20 were $19^{\circ} \mathrm{C}, 18.5^{\circ} \mathrm{C}$, $18.5^{\circ} \mathrm{C}, 17.5^{\circ} \mathrm{C}, 16^{\circ} \mathrm{C}$, respectively, as recorded experimentally. Data for simulation of heat of hydration generation according to Eq. (4) is shown in Fig. 17. This information was taken from for CEM I 42.5R (CB), and a volumetric content of $500 \mathrm{~kg} / \mathrm{m}^{3}$ of cement was considered for volumetric expression of $a$. All calculations were performed using the DIANA software [40].

\subsection{Results of the numerical simulations}

The numerical approach towards simulation of PCM behaviour in both embedded and discrete conditions will be validated by comparing its predictions with experimental results, presented next. The comparison of experimental and simulation results at control node for different cases are shown in Fig. 18a-e. From the observation of Fig. 18a-e, it can be confirmed that the numerical predictions for the T-t evolution match quite closely the ones measured by the thermocouples in the cases of REFM, MPCMM10 and GPCMM20, thus, very good agreement between numerical and experimental results can be observed, which validates the assumed simulation strategy. However, there is slightly shifting to the right side can be noticed in the case of MPCMM10. However, in the cases of GPCMM10 and MCPMM20 the maximum differences in the peak temperature reaches to $1.4^{\circ} \mathrm{C}$ and $0.7^{\circ} \mathrm{C}$, respectively. For every case, the temperature at the control point (M3) undergoes a rise to a peak due to cement hydration heat release and then a gradual decreasing trend up to the end.

Fig. 19 presents the temperature contours inside the models for the time frames when reached to their maximum temperatures. However, the temperature at the mortar layer is higher than centre of the model where the PCM located. Macro capsule core PCM causes change in the fashion trend for the counters, thus, allowing to lower temperature experiences by mortar part when compared with distributed form of the PCM into the mortar.

Typical specification for concrete includes a maximum temperature and a minimum temperature differential [41]. According to the temperature contours in the mixture parts at time steps of 0.65 day, 0.67 day, 0.67 day, 0.8 day and 0.8 day, temperature differences from the centre to the surfaces of the mortars are $7.3^{\circ} \mathrm{C}$, $1{ }^{\circ} \mathrm{C}, 2.8^{\circ} \mathrm{C}, 6.1^{\circ} \mathrm{C}$ and $6.2^{\circ} \mathrm{C}$ for REFM, MPCMM10, MPCMM20, GPCMM10 and GPCMM20, respectively, and such a temperature difference in the simulated cases with PCM incorporation may not lead to cracking, as temperature differential is reduced.

In order to further illustrate the effect of PCM in the mortar, Fig. 20 shows the calculated temperature profiles in the wall layer of the GPCMM20 and MPCMM20 at several instants within given environmental conditions. The selected instants that range 0.4 day-2.6 day (involves a heating/cooling ramp) for the case of GPCMM20 show that the mortar layer is enduring a quasiisothermal state at such stage (absorbed by latent heat storage/ release), while the temperatures in the outer layers (insulating materials) has significant gradients. This is due to the melting / solidification temperature ranges of used PCM in mortar which has onset temperature around $30^{\circ} \mathrm{C}$ and end temperature around
$40{ }^{\circ} \mathrm{C}$, as identified by horizontal dashed lines in Fig. 20a. Macro capsule core of PCM caused more uniform mortar's temperature profile within melting/solidification temperature range, along the mortar layer (see Fig. 20b). Similar findings and conclusions can be observed by analysis of the GPCMM10 and MPCMM10 specimens.

The fact that the temperature simulations in all cases match well, the measured values seems to further confirm the assumption that the heat generation function is not affected by the presence of PCM, as mentioned in Section 3.1 (even in the case of non-encapsulated PCM where direct contact with cement was possible).

\section{Conclusions}

In this research, mortars incorporating grated PCM and macro capsule core of PCM have been developed and experimentally characterized. Based on the test results, the following main conclusions can be drawn:

- The addition of grated pristine PCM into the mortar has led to $13 \%$ and $17 \%$ reduction of the density when compared with the reference mortar (without PCM). These mortars incorporating PCM comply with the light weight mortar values for construction applications, where for example, a lower dead load value of the structure is desirable.

- The thermal conductivity values for the PCM mortars was reduced by $20 \%$ and $40 \%$ for GPCMM 10 and GPCMM20, respectively, when compared with the reference mortar due to the lower conductivity of PCMs.

- Adding PCM leads to the reduction of the average compressive and flexural strength, however it still presents values compatible with possible structural use. In fact, the addition of $10 \%$ and $20 \%$ grated PCM revealed a compressive strength of $32 \mathrm{MPa}$ and $20 \mathrm{MPa}$, respectively, which is compatible with some structural applications.

- Overall thermal characterization tests have demonstrated the reduction of temperature rise, enhancement of thermal capacity of the mortar incorporating PCM.

- The heat transfer performance tests revealed that the dispersed form of PCM or macrocapsule cores of PCM has a beneficial effect over the heat gain energy.

- The heat release rate of cement hydration of mixtures with PCM were effectively changed by the two strategies of PCM incorporation into the mortars.

- Successful experimental validation was achieved, providing a transient thermal base model to predict temperature profile evolution within mortar containing PCMs in the both forms herein used.

From the calibrated numerical simulations using DIANA software it was also demonstrated that PCMs can reduce high temperature fluctuations in the early ages and flatten temperature swings in their melting temperature range. As a final note, this paper clearly proves that, through simulation tools, properly designed mortar/concrete mixes with plausible percentage of PCM incorporation in the mix have a significant potential to reduce temperature peaks/gradients induced by heat of hydration and have a positive contribution towards the reduction of thermal cracking risk in early ages. However, it is noted that further research is needed to assess the kind of trade-off brought about by the alterations in mechanical properties that is caused by the introduction of PCM in the mix: indeed, a reduction of tensile strength (and alteration of other properties) could potentially bring negative effects on the risk of cracking that diminish or even surpass the benefits 
attained by the temperature peak/gradient reduction achieved through PCM incorporation. These are however effects whose study will demand a dedicated research on several relevant properties of cement-based materials (mortar/concrete) containing incorporated PCM through the techniques mentioned in this paper (or others), namely E-modulus, creep behaviour, tensile strength, shrinkage, thermal expansion coefficient. Their intricate interplay in the thermo-mechanical behaviour of concrete at early ages would then require a combination of experimental validation (e.g. through use of a TSTM - Temperature Stress Testing Machine) and numerical simulation (thermo-mechanical analyses).

\section{Declaration of Competing Interest}

The authors declare that they have no known competing financial interests or personal relationships that could have appeared to influence the work reported in this paper.

\section{Acknowledgments}

The authors gratefully acknowledge the Foundation for Science and Technology (FCT) for the financial support to: the Research Unit RISCO (FCT/UID/ECI/04450/2013), the Research Unit ISISE (POCI-01-0145-FEDER-007633); the post-doc scholarship grant SFRH/BPD/116022/2016; the Research Project IntegraCrete PTDC/ECM-EST/1056/2014 (POCI-01-0145-FEDER-016841).

\section{References}

[1] J. Bilčík, R. Sonnenschein, N. Gažovičová, Causes of early-age thermal cracking of concrete foundation slabs and their reinforcement to control the cracking, Slovak J. Civ. Eng. 25 (2017) 8-14.

[2] Nicholas J. Carino, James R. Clifton. Prediction of Cracking in Reinforced Concrete Structures, NISTIR Report No.5634, 51 pp, 1995.

[3] A.M. Neville, in: Properties of Concrete, fifth edition., Pearson Education, Limited, 2011, p. 2865.

[4] G.N. Sant, Fundamental Investigations Related to the Mitigation of Volume Changes in Cement-Based Materials at Early Ages, Purdue University, 2009

[5] D.P. Bentz, R. Turpin, Potential applications of phase change materials in concrete technology, Cem. Concr. Compos. 29 (2007) 527-532.

[6] C. Qian, G. Gao, C. Zhu, Z. Guo, Influence of phase change materials on temperature rise caused by hydration heat evolution of cement-based materials, Mag. Concr. Res. 62 (2010) 789-794.

[7] F. Fernandes, S. Manari, M. Aguayo, K. Santos, T. Oey, Z. Wei, et al., On the feasibility of using phase change materials (PCMs) to mitigate thermal cracking in cementitious materials, Cem. Concr. Compos. 51 (2014) 14-26.

[8] C. Qian, G. Gao, Reduction of interior temperature of mass concrete using suspension of phase change materials as cooling fluid, Constr. Build. Mater. 26 (2012) 527-531

[9] P. Thaicham, M.B. Gadi, S.B. Riffat. An investigation of microencapsulated phase change material slurry as a heat-transfer fluid in a closed-loop system, 2004.

[10] J.A. Duffie, W.A. Beckman, Solar Engineering of Thermal Processes, John Wiley \& Sons, 2013.

[11] M. Hunger, A. Entrop, I. Mandilaras, H. Brouwers, M. Founti, The behavior of self-compacting concrete containing micro-encapsulated phase change materials, Cem. Concr. Compos. 31 (2009) 731-743.

[12] D. Zhang, Z. Li, J. Zhou, K. Wu, Development of thermal energy storage concrete, Cem. Concr. Res. 34 (2004) 927-934.

[13] A. Jayalath, R. San Nicolas, M. Sofi, R. Shanks, T. Ngo, L. Aye, et al., Properties of cementitious mortar and concrete containing micro-encapsulated phase change materials, Constr. Build. Mater. 120 (2016) 408-417.

[14] Y.-R. Kim, B.-S. Khil, S.-J. Jang, W.-C. Choi, H.-D. Yun, Effect of barium-based phase change material (PCM) to control the heat of hydration on the mechanical properties of mass concrete, Thermochim. Acta 613 (2015) 100107.
[15] B. Šavija, E. Schlangen, Use of phase change materials (PCMs) to mitigate early age thermal cracking in concrete: theoretical considerations, Constr. Build. Mater. 126 (2016) 332-344.

[16] Miguel Azenha, Numerical Simulation of the Structural Behaviour of Concrete Since its Early Ages PhD thesis, University of Porto, 2009.

[17] M. Kheradmand, M. Azenha, J.L.B. de Aguiar, J. Castro-Gomes, Experimental and numerical studies of hybrid PCM embedded in plastering mortar for enhanced thermal behaviour of buildings, Energy 94 (2016) 250-261.

[18] Jonna Manie, DIANA-Finite Element Analysis. User's Manual: Release 10.2, TNO Building Construction and Research, Delft, The Netherlands, 2017.

[19] ASTM C150, Standard Specification for Portland Cement, Annual Book of ASTM Standards, 1994.

[20] RUBITHERM ${ }^{\circledR}$. Technologies GmbH PCM technology and development https:// www.rubitherm.eu/en/about-us.html, 2017.

[21] M.L. Sandra Cunha, José B. Aguiar, Influence of adding phase change materials on the physical and mechanical properties of cement mortars, Constr. Build. Mater. 127 (2016) 1-10.

[22] TU1404. Towards the next generation of standards for service life of cementbased materials and structures RRT+ Main phase of the Extended Round Robin Testing programme for TU1404 TESTING PROTOCOLS, 2016.

[23] EN ISO 11357-1. Plastics - differential scanning calorimetry (DSC) Part 1: General principles DIN Deutsches Institut für Normung e.V. Berlin, 1997.

[24] EN 1015-3, Methods of Test for Mortar for Masonry - Part 3: Determination of Consistence of Fresh Mortar (by Flow Table), European Committee for Standardization (CEN), 2004.

[25] EN 480-1, Admixtures for Concrete, Mortar and Grout. Test methods. Reference Concrete and Reference Mortar for Testing, European Standard, 2014.

[26] EN 1015-10, Methods of Test for Mortar for Masonry, European Committee for Standardization (CEN), 2006.

[27] ISO:8301. Thermal insulation: determination of steady state thermal resistance and related properties, heat flow meter apparatus, 1991.

[28] B. EN. 1015-11, Methods of Test for Mortar for Masonry-Part 11: Determination of Flexural and Compressive Strength of Hardened Mortar, European Committee for Standardization, Brussels, 1999.

[29] W.T. Hongzhi Cui, Qinghua Qin, Feng Xing, Wenyu Liao, Haibo Wen, Development of structural-functional integrated energy storage concrete with innovative macro-encapsulated PCM by hollow steel ball, Appl. Energy 185 (2017) 107-118.

[30] J.S. Sayanthan Ramakrishnan, Xiaoming Wang, Morshed Alam, John Wilson, A novel paraffin/expanded perlite composite phase change material for prevention of PCM leakage in cementitious composites, Appl. Energy 157 (2015) 85-94.

[31] X.W. Sayanthan Ramakrishnan, Jay Sanjayan, John Wilson, hermal performance assessment of phase change material integrated cementitious composites in buildings: experimental and numerical approach, Appl. Energy 207 (2017) 654-664.

[32] H.C. Shazim Ali Memon, Tommy Y. Lo, Qiusheng Li, Development of structural-functional integrated concrete with macro-encapsulated PCM for thermal energy storage, Appl. Energy 150 (2015) 245-257.

[33] F. Luisa, C.C. Cabeza, Miquel Nogués, Marc Medrano, Ron Leppers, Oihana Zubillaga, Use of microencapsulated PCM in concrete walls for energy savings, Energy Build. 39 (2007) 113-119.

[34] Z.L. Biwan Xu, Paraffin/diatomite composite phase change material incorporated cement-based composite for thermal energy storage, Appl. Energy 105 (2013) 229-237.

[35] Y.X. Pania Meshgin, Yue Li, Utilization of phase change materials and rubber particles to improve thermal and mechanical properties of mortar, Constr. Build. Mater. 28 (2012) 713-721.

[36] D. Incropera, L. Bergman, Fundamentals of Heat and Mass Transfer, Sexta edição., Editora Wiley, Ano, 2006.

[37] M. Azenha, R. Faria, H. Figueiras, Thermography as a technique for monitoring early age temperatures of hardening concrete, Constr. Build. Mater. 25 (2011) 4232-4240.

[38] P. Lamberg, R. Lehtiniemi, A.-M. Henell, Numerical and experimental investigation of melting and freezing processes in phase change material storage, Int. J. Therm. Sci. 43 (2004) 277-287.

[39] AS-S. Panagiotis Kladisios, Using phase change materials in photovoltaic systems for cell temperature reduction: a finite difference simulation approach, J. Therm. Eng. 2 (2016) 897-906.

[40] DIANA Finite Element Analysis User's Manual-Release 10.2. TNO DIANA BV Netherlands, 2017.

[41] G.L. Yonghui Huang, Shiping Huang Rui Rao, Hu Changfu, Experimental and finite element investigations on the temperature field of a massive bridge pier caused by the hydration heat of concrete, Constr. Build. Mater. 192 (2018) 240-252. 